\section{Check for updates}

Cite this: Mater. Adv., 2022, 3, 1905

Received 30th September 2021, Accepted 9th January 2022

DOI: $10.1039 / \mathrm{d} 1 \mathrm{ma} 00911 \mathrm{~g}$

rsc.li/materials-advances

\title{
Modulating the porosity of carbons for improved adsorption of hydrogen, carbon dioxide, and methane: a review
}

\author{
L. Scott Blankenship (D) * and Robert Mokaya (D) *
}

\begin{abstract}
Porous carbons provide a low-cost route to a highly stable material for the adsorption of various gases. In particular, activated carbons (ACs) and zeolite templated carbons (ZTCs) show promise in their ability to capture and store environmentally relevant small molecules such as hydrogen, carbon dioxide and methane. Indeed biogas upgrading and methane storage are already partially commercialised. While ZTCs offer precise control over porosity, ACs have the advantage of being easy to synthesise from a wide range of sources. This review examines state-of-the-art techniques to control the porosity of both ACs and ZTCs in order to fine-tune their ability towards the capture and storage of various gases under different pressure and temperature applications.
\end{abstract}

\section{Introduction}

The current climate and ecological emergency threatens all life on planet earth, and is largely caused by incessant anthropogenic emissions of greenhouse gases. The resultant climate

School of Chemistry, University of Nottingham, University Park, Nottingham, NG7 2RD, UK. E-mail: leo.blankenship@nottingham.ac.uk,r.mokaya@nottingham.ac.uk change, which is already causing extreme weather events and is threatening mass extinction, is well underway but the full extent of effects of the climate crisis are yet to come. ${ }^{1,2}$ In order to keep within the temperature limits prescribed by the Paris Agreement, ${ }^{3}$ it is necessary not only to drastically reduce global net greenhouse gas (GHG) emissions by reducing consumption and transitioning to 'green' energy sources but also to capture $\mathrm{CO}_{2}$ and $\mathrm{CH}_{4}$ in the interim. ${ }^{3-6}$ Although bioremediation of

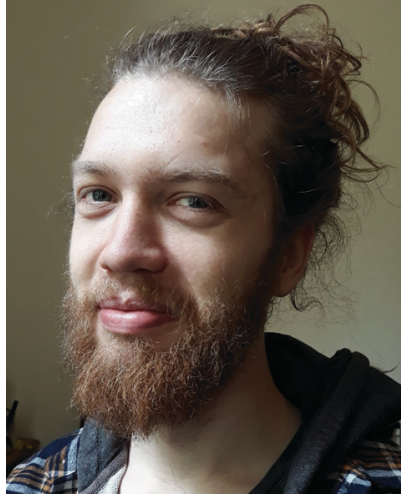

L. Scott Blankenship
L. Scott Blankenship is a PhD student in the Mokaya group at the University of Nottingham, and obtained his MSc in the same group in 2016 working on porous carbons from cigarette butts for $\mathrm{H}_{2}$ storage and $\mathrm{CO}_{2}$ capture. His research interests focus on critical evaluation of porosimetric methods for carbons and the ability of these methods to predict uptake of environmentally relevant small molecules.

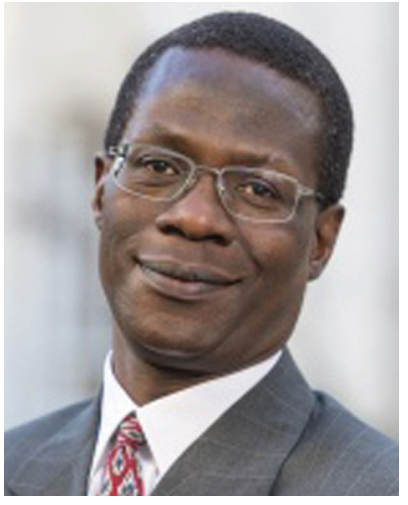

Robert Mokaya
Robert Mokaya received his BSc in Chemistry from the University of Nairobi in 1988 after which he spent a year working for Unilever in Kenya. He was awarded his $\mathrm{PhD}$ from the University of Cambridge in 1992. In 1992, he was elected to a Research Fellowship at Trinity College, Cambridge and in 1996 was awarded an EPSRC Advanced Fellowship. He joined the School of Chemistry in Nottingham, as a lecturer in Materials Chemistry in 2000, where he is Professor of Materials Chemistry. His research interests are on the design, synthesis and characterisation of new forms of sustainable porous materials and the study of their structure-property relations. The research involves exploring fundamentally new synthesis methods that are simpler, cheaper, and more efficient and offer valorisation routes to materials with optimised properties for targeted sustainable energy applications. 
carbon capturing ecosystems has a great role to play in the offsetting of GHG emissions, it is insufficiently expedient to keep up with the reduction in emissions necessitated by both the aforementioned Paris Climate Agreement and the UK's limited goal of achieving net zero emissions by $2050 .^{3,6-8}$

These factors necessitate development of novel, low cost $\mathrm{CO}_{2}$ capture technologies. ${ }^{9}$ Additionally the global economy must rapidly transition away from fossil fuels as vehicular energy sources and towards cleaner, renewable fuels such as natural gas $\left(\mathrm{CH}_{4}\right)$ and $\mathrm{H}_{2} \cdot{ }^{10-12}$ Although natural gas is not a carbon neutral fuel, it is produced sustainably from the breakdown of biomass and releases much less $\mathrm{CO}_{2}$ and other pollutants than other fossil fuels. ${ }^{13,14}$ As for $\mathrm{H}_{2}$, the sole product of its combustion is water making it a carbon-neutral fuel at the point of use. ${ }^{10}$ The difficulty with storing or capturing $\mathrm{CO}_{2}, \mathrm{CH}_{4}$ and $\mathrm{H}_{2}$ is that they all exist in the gas phase under ambient conditions. As a result, the challenge becomes both economic and practical how these gases can be stored and transported in a cost and spaceefficient way. ${ }^{10,14-22}$ Currently, industrial $\mathrm{CO}_{2}$ capture is achieved principally through reaction with liquid amines in the presence of water to form aqueous ammonium bicarbonates, ${ }^{23,24}$ while commercial technologies for the storage of natural gas $/ \mathrm{CH}_{4}$ and $\mathrm{H}_{2}$ rely on compression or liquefaction. ${ }^{10,14,18,20-22,25}$ The cost of liquid amine capture is principally a result of its relatively low $\mathrm{CO}_{2}$ capacity as well as energy requirements for regeneration of the amine from the ammonium bicarbonate. Though compression or liquefaction of gaseous fuels does not come with the same regeneration issues present in chemical capture of $\mathrm{CO}_{2}$, it is plagued by the high energy costs of maintaining the high pressures and/or low temperatures required. ${ }^{14,20}$ In the case of compressed gases the weight of sufficiently robust containers needed to maintain these pressures is very high, leading to energy losses for on-board applications. ${ }^{22}$

Promising alternative methods of gas storage involve chemical (chemisorption) or physical (physisorption) adsorption onto a suitable solid material. Physisorption has the distinct advantage over chemisorption of facile regeneration of the adsorbate by decreasing pressure or increasing temperature. Microporous adsorbents such as Metal Organic Frameworks (MOFs), ${ }^{26-28}$ porous polymers, ${ }^{29}$ Porous Inorganic Membranes, ${ }^{30}$ and zeolites ${ }^{31-33}$ present possible storage solutions but have the disadvantage of relatively high cost of production and/or finite lifecycles due to thermal instability or undesirable reactivity with contaminants such as water. On the other hand, porous carbons provide a storage medium that is relatively inexpensive to produce and extremely thermally and chemically stable. ${ }^{18,20,34}$ Furthermore, the porosity of carbons can be tailored to be selective for specific adsorbates and adsorption conditions. ${ }^{20,35-37}$

Porous sorbents are actually already beginning to see some commercial use in the capture/storage of small molecules. This is particularly evident for $\mathrm{CH}_{4}$, which is already being used as an on-board fuel. ${ }^{38-42}$ It is principally stored via compression (CNG) or liquefaction (LNG). ${ }^{38,39}$ However, adsorbed natural gas (ANG) is now competitive with the CNG and LNG as a result of the much higher energy density than CNG, and is already commercially available. ${ }^{43,44}$ As pressures required for ANG are significantly lower than those for CNG, ANG infrastructure is less costly. ${ }^{38,40,45,46}$ Additionally, adsorption of $\mathrm{CH}_{4}$ poses a much lower safety risk relative to compression and improves overall efficiency at point of use. ${ }^{12,46}$ Due to its low cost, activated carbons are used as the adsorbents in on-board applications as well as at fuelling stations. ${ }^{43,44}$ Additionally, porous carbons are in commercial use for the upgrading of biogas (typically $\sim 60 \% \mathrm{CH}_{4}$ ) by selective removal of $\mathrm{H}_{2} \mathrm{O}, \mathrm{CO}_{2}$ and $\mathrm{H}_{2} \mathrm{~S}$ resulting in improved $\mathrm{CH}_{4}$ concentration of over $98 \% .{ }^{44,47,48}$ The principal problem with porous materials for this application is imperfect selectivity resulting in so-called methane slip, wherein some methane is lost to the sorbent. ${ }^{4-50}$ In theory this problem can be mitigated by finely tuning pore widths and/or surface chemistry.

Porous carbons fall into four main categories; activated carbons, carbonised frameworks, templated carbons, and carbide-derived carbons. ${ }^{51}$ Of these, the simplest to produce are activated carbons, which in the case of so-called chemical activation, require simple heating of a carbonised (typically graphitic) material with an activating agent to generate pores. In fact, the initial carbonisation step can be performed simultaneously with the so-called activation step..$^{20,52}$ The perceived disadvantage of this technique is that the amorphous nature of the product means tuning of the pore size can be difficult. Framework carbonisation involves pyrolysis of an already porous organic material such as an aerogel or other polymer network. ${ }^{53-55}$ Templating is one of the newer techniques and is performed by depositing a carbon rich material onto some inorganic template (typically silicas or zeolites) with the desired pore size and surface area, followed by heat treatment in order to form a graphenic crystalline structure within the template pores, before removing the template. ${ }^{34,51,56}$ Finally carbidederived carbons, which use metal carbides as starting material, allow for tuning of porosity at the atomic level. This is possible as suitable carbides are selected according to their lattice spacing, wherein removal of the metal counterion generates pure carbon with pore channels whose size is determined by the precursor's lattice geometry. ${ }^{57-59}$ Broadly, porous carbons for small molecule gas adsorption should be microporous and have high surface area and pore volume. ${ }^{18,60-63}$ Although it is possible to achieve porous carbons with such characteristics via any of the aforementioned routes, by far the most popular methods are activation and templating using zeolites and as such these form the subject of this review. For both of these processes, the challenge is tuning the porosity of resultant carbons to optimise uptake performance for specific adsorbates and/or adsorption conditions; in the case of activated carbons (ACs) this centres on techniques to narrow the pore size distribution (PSD), ${ }^{20}$ whilst with zeolite templated carbons (ZTCs) improvements come via more improved replication of the template structure. ${ }^{34,56}$

Gas uptake and molecular selectivity of ZTCs and ACs can also be improved chemically by introducing, as dopants, moieties with affinities for the targeted adsorbate. ${ }^{63-68}$ This review however, focuses on improvements in physisorption of small 
gas molecules by porous carbons achieved by tailoring the size, shape, and abundance of pore channels available to the adsorbate. Any reference herein to doping of the carbon structure with heteroatoms is made in the context of the effect on pore structure.

\section{Synthesis of porous carbons}

Methods for synthesizing porous carbons can be split up into two broad groups; top-down or bottom-up. A top-down method takes an existing carbon or carbonaceous material and develops porosity in it by etching away material; this process is commonly known as activation. ${ }^{20}$ Conversely, bottom-up methods consist of constructing the carbon structure from its building blocks in such a way that voids or pores are formed, often with the use of a porous template. Such templates include mesoporous silica, ${ }^{69,70}$ micro-phase separated block copolymers ${ }^{71}$ or even MOFs, ${ }^{72,73}$ however perhaps the most well-known microporous templates are zeolites where the product of such a process is known as zeolite-templated carbon (ZTC). ${ }^{34}$ Bottom-up synthesis can also occur in the absence of a template, for example via the direct carbonization of organic crystals. ${ }^{74}$

\subsection{Activation of carbon-rich precursors}

Activation, here meaning the development of porosity in a carbon precursor, can be achieved by either physical or chemical means. Physical activation is a two-step process whereby the precursor is first pyrolised at $400-900{ }^{\circ} \mathrm{C}$ in an inert atmosphere, in order to increase carbon content. Thereafter the sample is exposed to an oxidizing gas at $350-1000{ }^{\circ} \mathrm{C}$ in order to develop pores. Chemical activation however, can take place in a single step wherein the carbon precursor is mixed with an activating agent - also known as a porogen (such as alkali metal hydroxides, $\mathrm{H}_{3} \mathrm{PO}_{4}$, or $\mathrm{ZnCl}_{2}$ ), then pyrolised at $450-900{ }^{\circ} \mathrm{C}^{20}{ }^{2}$ Precursors can essentially be any organic matter, and include biomass such as wood, ${ }^{75,76}$ fruit seeds, ${ }^{35,77}$ grass, ${ }^{78}$ and refined biopolymers. ${ }^{79}$ The degree of activation, i.e. the extent of porosity development, can be improved by precarbonisation of the precursor. ${ }^{80-82}$ Newer forms of carbon such as templated carbons, nanotubes, and carbide derived carbons (CDCs) have also been activated to improve their porosity. ${ }^{83-88}$

It should be noted that physical activation can be achieved without addition of an oxidising gas because volatile components of the precursor are converted to (among other things) oxidising gases on pyrolysis resulting in the development of small micropores. In the case of biomass carbonisation in the absence of a porogen, porosity and structure are maintained in the resulting so-called biochar material. ${ }^{89-91}$

2.1.1. Physical activation. As mentioned above, the first step in physical activation is pyrolysis of the precursor in an inert atmosphere (typically under nitrogen). This removes the majority of volatiles from the precursor as well as carbonizing it. By-products of the pyrolysis are burned off by the oxygen in the activating agent $\left(\mathrm{CO}_{2}\right.$, air or steam) during the gasification step, which results in opening of some larger, closed pores. Further pores in the micropore region are developed as the porogen burns off less stable parts of the carbon skeleton. The porosity of the resultant activated carbon is dependent on the composition of the precursor, choice of activating agent and temperature used at both steps. For a given activating agentprecursor pair, porosity development is generally improved by increasing activation temperature. ${ }^{20,92-94}$ However, this comes with a broadening in the PSD, which is undesirable for gas uptake applications at low pressure ${ }^{63,95-97}$ Such broad porosity can nonetheless be useful in high pressure or so-called pressure-swing applications. ${ }^{35,98-101}$

Activation with $\mathrm{CO}_{2}$ and steam generally result in higher yields than using air as a porogen. This is because the reaction between carbon and oxygen in the air is highly exothermic and leads to a much faster reaction, burning off more of the carbon. ${ }^{20}$ This does however mean that much lower temperatures are required for activation using air, as compared to $\mathrm{CO}_{2}$ and steam. ${ }^{52,102,103}$ Steam and $\mathrm{CO}_{2}$ are nonetheless the preferred physical activating agents due to the aforementioned problems with air. ${ }^{20}$ Steam is generally characterised as the more reactive porogen of the two, requiring lower activation temperatures than $\mathrm{CO}_{2} \cdot{ }^{92,104,105}$ There is however still some disagreement as to what type of porosity is developed by each activating agent. ${ }^{105-108}$

2.1.2. Chemical activation. Chemical activation is favoured for the production of porous carbons for use in small gas molecule storage as it results in high surface area carbons whose porosity is primarily in the micropore region. Furthermore, this microporosity can be tailored via experimental conditions to be within a narrow pore size range. In addition, the process is more efficient than physical activation as synthesis usually occurs in a single, low temperature step and results in higher carbon yields. ${ }^{20,109}$

Chemical activating agents can be divided into two groups according to their activation mechanism; the first group are dehydrating agents such as $\mathrm{H}_{3} \mathrm{PO}_{4}$ and $\mathrm{ZnCl}_{2}$ wherein the dehydration of the carbonaceous structure, triggered by the action of the activating agent leads to the formation of crosslinkages. ${ }^{110,111}$ This in turn triggers condensation of the structure around the activating compound and its hydrates. Pore size is thus limited by size of these compounds. Further, the breadth of the PSD is a function of the variation in molecular sizes of the activating agent and its hydrates. For example, activated carbons produced using $\mathrm{ZnCl}_{2}$ have narrow PSDs as structural condensation occurs around $\mathrm{ZnCl}_{2}$ and its hydrates which are of similar size. ${ }^{112}$ On the other hand, $\mathrm{H}_{3} \mathrm{PO}_{4}$ is converted to molecules with a broader range of sizes such as $\mathrm{H}_{4} \mathrm{P}_{2} \mathrm{O}_{5}$ and $\mathrm{H}_{13} \mathrm{P}_{11} \mathrm{O}_{34}$ resulting in a heterogeneous PSD, regardless of activating conditions. ${ }^{113}$

Despite the ubiquity of $\mathrm{KOH}$ as a porogen in the literature, the mechanism of activation is a matter of some debate. ${ }^{20,109,114-121}$ Nonetheless, there is a broad agreement that pore formation occurs via three principle processes: $:^{20,109,114-116,118}$ (i) chemical activation wherein redox reactions between $\mathrm{K}$ compounds and the carbon framework occur; (ii) formation of the physical activating 
agents $\mathrm{CO}_{2}$ and $\mathrm{H}_{2} \mathrm{O}$ which induce gasification of carbon to further develop porosity; (iii) the intercalation of metallic $\mathrm{K}$ between graphitic sheets. Washing of the sample removes both intercalated $\mathrm{K}$ as well as $\mathrm{K}$ oxides and carbonates, resulting in a permanently porous carbon. There is inconsistent evidence on the exact nature and validity of processes (i) and (iii). For example, work by LinaresSolano indicates that (i) occurs directly via the oxidation of carbon by $\mathrm{KOH}\left(\right.$ eqn (1)). ${ }^{116,117}$

$$
6 \mathrm{KOH}+2 \mathrm{C} \rightarrow 2 \mathrm{~K}+3 \mathrm{H}_{2}+2 \mathrm{~K}_{2} \mathrm{CO}_{3}
$$

On the other hand, Otowa et al. argue that $\mathrm{KOH}$ first dehydrates to form $\mathrm{K}_{2} \mathrm{O}$ and $\mathrm{H}_{2} \mathrm{O}$ (eqn (2)), and $\mathrm{C}$ is oxidised by $\mathrm{H}_{2} \mathrm{O}$ (eqn (3) and (4)). ${ }^{115}$

$$
\begin{gathered}
2 \mathrm{KOH} \rightarrow \mathrm{K}_{2} \mathrm{O}+\mathrm{H}_{2} \mathrm{O} \\
\mathrm{C}+\mathrm{H}_{2} \mathrm{O} \rightarrow \mathrm{CO}+\mathrm{H}_{2} \\
\mathrm{CO}+\mathrm{H}_{2} \mathrm{O} \rightarrow \mathrm{CO}_{2}+\mathrm{H}_{2}
\end{gathered}
$$

As for (iii), some researchers accept that above $700{ }^{\circ} \mathrm{C} \mathrm{K}_{2} \mathrm{CO}_{3}$ and $\mathrm{K}_{2} \mathrm{O}$ is reduced by $\mathrm{C}$ to form metallic $\mathrm{K},{ }^{20,116}$ and indeed there is some evidence that this reaction can occur and furthermore that $\mathrm{K}$ can intercalate with graphite. ${ }^{122,123}$ However, the formation of metallic $\mathrm{K}$ is not observed industrially. It should also be noted that the mechanisms discussed above preclude the consideration of heteroatoms. There is evidence, for example that for nitrogen-rich precursors cyanide compounds can be produced during activation with $\mathrm{KOH} .^{124,125}$ In the case of $\mathrm{NaOH}$ activation, the mechanism is believed to be similar (and just as ill-defined), however there is no evidence that $\mathrm{Na}$ can intercalate as in (iii). ${ }^{117,119}$

Chemical activation using $\mathrm{KOH}$ is noted for the distinct advantage of giving a higher degree of control over the PSD as compared with other activating agents. ${ }^{20,79,126,127}$ Though PSDS for carbons derived using small amounts of $\mathrm{KOH}$ or $\mathrm{NaOH}$ are typically narrow, significant broadening occurs with increasing $\mathrm{MOH} /$ precursor ratio. ${ }^{128-130}$ For applications in which high porosity materials with narrow PSDs are required, alkali metal carbonates and bicarbonates as well as oxalates show significant promise. ${ }^{131-134}$ These porogens have been shown to be significantly less corrosive than their hydroxide counterparts, yet produce materials with significant surface area, particularly in the micropore region, ${ }^{135-138}$ and are discussed in more detail in Section 4.1.1.

While oxidative chemical activation is heavily favoured in the literature due to its ability to produce carbons with extremely high surface areas, it comes with the disadvantage of resulting in significant loss of material. Dehydrating agents are non-destructive thus result in much higher yields. In addition, it has been shown that air, as opposed to an inert gas may be used in such scenarios, for example Fierro et al. produced carbons from lignin activated with $\mathrm{H}_{3} \mathrm{PO}_{4}$ at temperatures up to $600{ }^{\circ} \mathrm{C} .{ }^{139,140}$

Pre-carbonisation methods. The porosity of carbons can be improved by subjecting the precursor to an initial carbonisation step before activation. This results in the partial graphitisation of the material and increases the carbon content, accompanied by a reduction in concentration of heteroatoms. This means that fewer oxidising gases are released upon activation resulting in more controlled activation and thus a narrower PSD, less pore collapse and generally higher surface area. Carbonaceous matter can exist in carbonised form such as coal, pitch or tar and can be converted to high surface area activated carbon in a single step. ${ }^{141-143}$ Alternatively, biomass can be hydrothermally carbonised by heating in water under high pressure to generate carbonaceous matter composed of microspheres which possess a hydrophobic core and hydrophilic shell, of which the latter is more susceptible to chemical activation. ${ }^{144-147}$ Another route is so-called air- or flash carbonisation, which is achieved by briefly interrupting the inert atmosphere used during pyrolysis by injection of air into the system. ${ }^{35,80,81}$

2.1.3. Microwave activation. Conventionally the thermal treatment(s) of precursors in a chemical and/or physical activation process is achieved via convective and conductive heating of the sample in a fixed bed. This can result in uneven heating of the sample, and thus inconsistency in pore structure across the derived AC. To mitigate this the heating is usually accomplished via a slow continuous ramp, and with a long isothermal period (the dwell time), which result in the activation lasting several hours. The use of microwave radiation as a heat source provides more even heating and thus much faster activated carbon synthesis; reaction times are on the order of a few minutes. ${ }^{148}$ It has been shown that pyrolysis and/or activation using microwaves result in ACs with textural properties similar to those derived via conventional methods. ${ }^{67,149,150}$

2.1.4. Physicochemical activation. In some cases the porosity of ACs derived via chemical activation using dehydrating agents can be extended by physical activation. The initial dehydration step causes development of micropores, while subsequent treatment with steam or $\mathrm{CO}_{2}$ produces larger pores. $^{52}$ This results in a broader and/or multimodal PSD, ${ }^{151,152}$ which is particularly suited to methane/natural gas storage.

2.1.5. Carbon molecular sieves. Molecular sieves are a class of porous materials with very narrow PSDs, which make them useful in gas separation applications wherein species are separated according to their size. ${ }^{153-157}$ These materials are derivatives of porous materials such as silicates and zeolites. ${ }^{154,158,159}$ While activated carbons typically have heterogeneous PSDs, if they are synthesised or adapted to change pore entrance dimensions to a single pore size they are known as carbon molecular sieves (CMSs). ${ }^{157,160}$ Prior to the explosion in ZTC research, templated carbons were often referred to as $\mathrm{CMSs}^{69}{ }^{69}$ however the term is now restricted to non-templated carbons with narrow PSDs. On an industrial scale, CMSs are typically synthesised by depositing pyrolytic carbon at the mouth of the pores in activated carbons, resulting in uniform pore entrances. ${ }^{160-162}$ This results in so-called bottle-neck pores, wherein the pore entrance is narrower than the main pore channel. ${ }^{157}$ CMSs can also be synthesised directly by activation of an appropriate precursor(s) under precise conditions. Suitable porogens include nitric acid or oxygen and initial activation is followed by a final heating stage. ${ }^{163}$ Suitable precursors 
include polymers, some coals, and woody biomass such as peach stones or coconut shells. ${ }^{156,157,161,163}$ Alternatively, pore entrance uniformity can be encouraged by mixing a precursor with a binder prior to pyrolysis. ${ }^{164}$

\subsection{Templating onto porous zeolitic structures}

Zeolites are three-dimensional uniform microporous crystalline framework structures. For aluminosilicates, the structure is based on silica networks where some of the $\mathrm{Si}^{4+}$ cations are replaced by $\mathrm{Al}^{3+}$, resulting in an overall negative charge for the framework. Cations such as $\mathrm{Na}^{+}, \mathrm{H}^{+}$or $\mathrm{NH}_{4}{ }^{+}$reside within the framework pores to balance the charge. ${ }^{154,165,166}$ More than 40 naturally occurring zeolites are known to exist, ${ }^{167}$ and while theoretical zeolites number in the thousands ${ }^{168}$ only ca. 200 have thus far been synthesised. ${ }^{169}$ The aforementioned uniformity of zeolitic micropores means they are interesting in their own right as gas sorption and separation materials. ${ }^{32,33,170}$ However, the chemical and thermal stability (under inert conditions) of some zeolites is lower than that of activated carbons. Interest in using zeolites as sacrificial templates for the preparation of porous carbons arises from a desire to improve the structural ordering of highly stable but totally amorphous porous carbon materials. ZTCs provide a route to uniformly porous graphenic microporous solids with porosity and thermochemical stability comparable to that of activated carbon. ${ }^{171}$ In addition, this regularity in structure leads to greater scope for functionalisation of the carbon surface. ${ }^{34,172}$

These improved characteristics necessitate more precise synthesis conditions. ZTCs can be divided into three types according to how graphenic the overall structure is, which is connected to the degree of replication of the template's pore channels ranging from type-I where near complete template replication is achieved, to type-III where the pore structure bears little resemblance to its template and possesses a high degree of graphene stacking. Type-II ZTCs are formed when the template is partially replicated, but there is still a high degree of graphiticity due to deposition of carbon on the outer surface of the template. ${ }^{34}$ The structural uniformity of the zeolite can only be conferred on the resultant ZTC (i.e. a type-I ZTC) when the template's pore structure is composed of large 3D channels. ${ }^{173-175}$ Specifically, pore entrances should contain a minimum of $12 \mathrm{O}$ atoms in the prototypical $\mathrm{Si}-\mathrm{O}-\mathrm{Si}$ ring which forms the zeolite channel opening to allow for uniform pore filling by the carbon monomer without risking pore blocking. ${ }^{34,176}$ Smaller pores or low dimensional pore networks always result in a disordered, graphitic structure (type-III) more akin to activated carbons. As most natural zeolites have small pore entrances, they typically yield poorly ordered ZTCs. To achieve type-I ZTCs, sufficient carbon monomer must be inserted evenly into the zeolite pores and allowed to polymerise before carbonisation. Thus two heating stages are required to achieve discrete, uniform graphenic

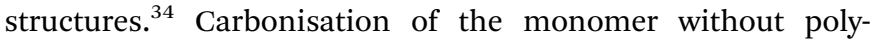
merisation can lead to partial uniformity with some graphene stacking (type-II) with a mixture of graphitic and graphenic ordering, while failure to achieve even distribution of monomer is likely to result in no replication of the template structure.
As type-I ZTCs typically have the highest degree of porosity $\left(A_{\mathrm{BET}}>2100 \mathrm{~m}^{2} \mathrm{~g}^{-1}\right)^{177}$ precise selection of zeolite, monomer, and activation conditions is vital for producing a ZTC with adventitious porosity for small molecule physisorption.

2.2.1. Liquid impregnation. Introduction of a carbonaceous precursor into zeolite pores can be achieved by simply inserting a carbon-rich liquid monomer into the channels. By heating the zeolite/monomer mixture, and with assistance from the catalytic action of the zeolite template, polymerisation occurs resulting in a zeolite-polymer composite. This is then carbonised by heating in an inert atmosphere. The most commonly used liquid monomer is furfuryl alcohol (FA), ${ }^{88,174,178-182}$ due to its ease of insertion into pores. ${ }^{34}$ However other monomers such as acrylonitrile, ${ }^{174}$ saccharides, ${ }^{183,184}$ and ethylene diamine $^{185}$ have also been studied as precursors. ZTCs derived via liquid impregnation (LI) typically poorly replicate the zeolite structure (resulting in a type-III structure) as it is difficult to insert sufficient precursor into the pores. ${ }^{34}$ Dissolved polymers such as lignin, ${ }^{186,187}$ and a co-polymer of sulfonic and maleic acids ${ }^{188}$ have also been used as carbon precursors but the resultant ZTCs have relatively low surface area and poorly replicate the zeolite pore structure. This is likely a result of inadequate pore penetration due to the size of precursor molecules relative to that of the pore entrance. $^{34}$

2.2.2. Chemical vapour deposition. In order to overcome the problem of inadequate pore penetration during ZTC synthesis presented by the liquid impregnation method, chemical vapour deposition (CVD) can be used. ${ }^{34,171}$ Introduction of sufficient carbon into the pores is achieved by using a small, unsaturated organic molecule in the gas phase such as methane, ${ }^{189}$ short-chain alkenes, ${ }^{64,179,190-193}$ acetylene ${ }^{194,195}$ or acetonitrile. ${ }^{61,64,83,179,182,190,196-198}$ CVD must be conducted at a temperature below the decomposition temperature $\left(\sim 600{ }^{\circ} \mathrm{C}\right)$ of the carbon source in order to maximise pore channel structure replication in the ZTC. This initial step results in the zeolite-catalysed conversion of the CVD source into disconnected polyaromatic hydrocarbons (PAHs). A second heating step at elevated temperature $\left(>800{ }^{\circ} \mathrm{C}\right)$ is needed to carbonise the PAHs and fully connect the pore network. Removal of the template without the second heat treatment step can result in a poorly connected (type-III) ZTC structure upon template removal. ${ }^{34,56}$ Improvements in porosity have been reported by incorporating two temperatures stages into the CVD step. ${ }^{190,195}$

2.2.3. Two-step method. ZTCs may also be constructed using LI followed by CVD, which offers some improvement in porosity relative to using either step alone. ${ }^{179,180}$ Porosity improvements are likely a result of more uniform pore filling by two or more carbon sources used in the steps. ${ }^{34} \mathrm{FA}$ is most commonly used as the LI precursor in this method as it provides good pore penetration. This is then followed by CVD using acetonitrile, ${ }^{179,190,199}$ ethylene ${ }^{61,179,180,182,190}$ or other small unsaturated hydrocarbons. ${ }^{200-203}$ Larger precursor molecules which would not normally produce good zeolite replication in an LI (such as lignin) or CVD (such as benzene) process can be employed in a combined process, resulting in improved 
textural characteristics relative to ZTCs produced via either CVD or LI alone. ${ }^{187,204,205}$

2.2.4. Template removal. In order to remove the zeolitic framework after the synthesis, it is typically necessary to wash with $\mathrm{HF}$ or some combination of $\mathrm{HF}$ washing and $\mathrm{HCl}$ reflux. ${ }^{34,182,192,193,206}$ The use of HF is impractical for industrial synthesis due to safety issues. Hedin and co-workers found that template removal could be achieved with a combination of $\mathrm{HCl}$ and $\mathrm{NaOH}$ for a silicoaluminophosphate-templated carbon, however this is likely due to less chemical robustness compared to a pure aluminosilicate framework. ${ }^{207} \mathrm{NaOH}$ has been shown to be at least partially effective in desilicating zeolites, so does show some promise for removal of actual zeolite templates from ZTCs, ${ }^{208}$ and has been attempted on a few occasions. ${ }^{176,209-211}$ Moon et al. found that washing with hot $\mathrm{NaOH}$ followed by $\mathrm{HCl}$ resulted in complete removal of $\mathrm{Al}$, but left residual $\mathrm{Si}$ in the resultant ZTCs. ${ }^{210}$ Ryoo and co-workers found the ash content of the carbon could be reduced to as low as $2.0 \mathrm{wt} \%$ with a combination of $\mathrm{NaOH}$ and $\mathrm{HCl}$ washing. This result however is constrained to zeolite-beta which has a higher proportion of $\mathrm{Si}-\mathrm{O}-\mathrm{Si}$ bonds which are more easily dissolved in $\mathrm{NaOH}$. On the other hand, zeolite-X and -Y with significantly higher $\mathrm{Al}$ content are more resistant to dissolution in $\mathrm{NaOH}$ and $\mathrm{HCl}$. Even in the case of zeolite-beta templated carbon, an $\mathrm{HF} / \mathrm{HCl}$ wash significantly outperforms $\mathrm{NaOH}$ and $\mathrm{HCl}$, resulting in an ash content of $0.5 \mathrm{wt} \%{ }^{211}$ Template dissolution with $\mathrm{NaOH}-\mathrm{HCl}$ on the other hand produces more oxygen-rich carbons, ${ }^{209,211}$ and may result in slight reductions in overall porosity of ZTCs relative to those washed in HF. ${ }^{211}$

\section{Textural characteristics for gas storage applications}

Desirable textural characteristics for gas storage are dependent on the adsorptive, temperature and pressure of interest. Fig. 1 and 2 show how different pressures can affect the optimal textural characteristics of carbons. A summary of relevant properties of common gaseous sorptives is shown in Table 1. In the literature, measurements are commonly taken at $25{ }^{\circ} \mathrm{C}$ for $\mathrm{H}_{2}, \mathrm{CO}_{2}$, and $\mathrm{CH}_{4}$ while -196 and $0{ }^{\circ} \mathrm{C}$ are also typical for
$\mathrm{H}_{2}$ and $\mathrm{CO}_{2}$ respectively. ${ }^{14,16,20,212,213}$ A series of isotherms at various temperatures for a given adsorbate-sample pair may also be reported to allow determination of isosteric heats of adsorption. ${ }^{214}$ The pressure range used in isotherm measurement may depend on sample porosity; adsorption will typically plateau at relatively low coverage for samples with low surface area thus the upper pressure used need not be very high. Typical reports include data up to $\sim 40$ bar for $\mathrm{CH}_{4}$ and $\mathrm{CO}_{2}$, while $\mathrm{H}_{2}$ uptake is more commonly measured up to $\sim 100$ bar. Of particular interest is the adsorption at 1 bar, however lower pressure such as 0.15 bar are also used for selectivity calculations especially in $\mathrm{CO}_{2}$ uptake studies. Increases in surface area and pore volume generally improve a sample's uptake of an adsorbate by supplying adsorbed molecules with more surface to interact with and greater volume to fill, respectively. This is however limited by pore size, which can differentiate an adsorbent as a good candidate for storing one gas but not another. ${ }^{63,91,215-217}$ As such, more detailed measures of porosity such as pore size distribution (PSD) and average pore size are used. Furthermore, low pressure adsorption of $\mathrm{CO}_{2}, \mathrm{CH}_{4}$ and $\mathrm{H}_{2}$ is dominated by micropores, and thus micropore surface area and volume is typically reported alongside the total values. ${ }^{218}$

\subsection{Pore size}

If pore width is less than the diameter of the adsorptive (see Table 1), adsorption will not occur within the pore - indeed even pores with diameters slightly greater than that of the molecule's kinetic diameter $\left(d_{\mathrm{k}}\right)$ can lead to extremely slow diffusion at low temperatures, meaning that equilibrium may take a long time (hours) to achieve. ${ }^{52,225,226}$ Additionally, optimum pore size has an upper limit due to the improvements in adsorption from field overlap when pore walls are sufficiently close together.

For small molecules like $\mathrm{H}_{2}, \mathrm{CO}_{2}$, and $\mathrm{CH}_{4}\left(d_{\mathrm{k}}=2.89,3.30\right.$, and $3.80 \AA$ A respectively), ${ }^{154,222,223}$ this means that highly microporous materials are the most suitable for physisorption (see Fig. 1). Optimal pore size for adsorption of a given molecule is proposed to be that which can hold two layers of the molecule. ${ }^{212,217,227}$ Fig. 1 shows how average pore size affects
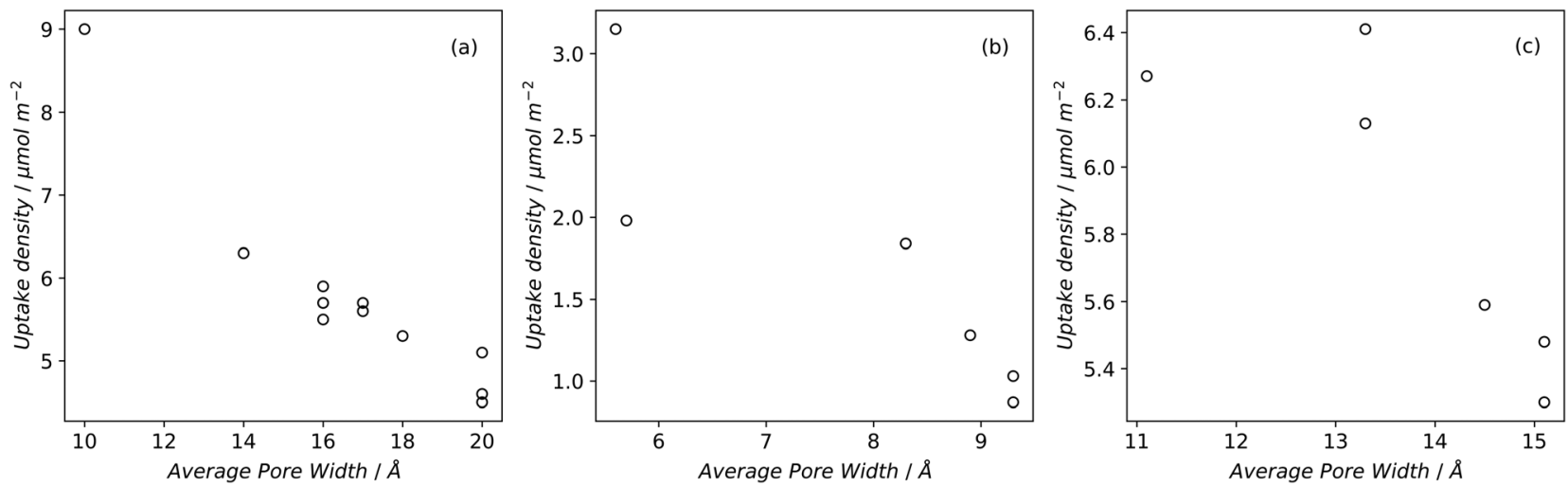

Fig. 1 Uptake densities of (a) $\mathrm{H}_{2}$ at 1 bar and $-196{ }^{\circ} \mathrm{C}$, (b) $\mathrm{CO}_{2}$ at 1 bar and $25^{\circ} \mathrm{C}$, and (c) $\mathrm{CH}_{4}$ at 65 bar and $25^{\circ} \mathrm{C}$ on carbons ${ }^{79,194,219}$ as a function of average pore size. 

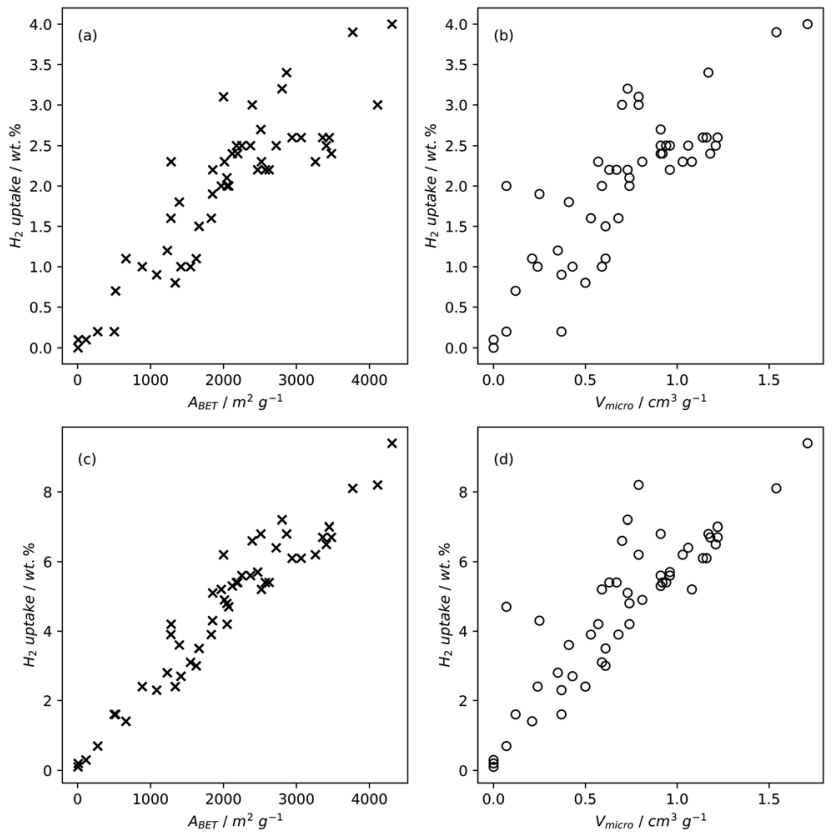

Fig. $2 \mathrm{H}_{2}$ uptake of carbons at $-196{ }^{\circ} \mathrm{C}$ and 1 bar (a) and (b) or 20 bar (c) and (d) as a function of BET surface area (a) and (c) or micropore volume (b) and (d). ${ }^{79,82,83,196,220,221}$

Table 1 Physical properties of commonly stored gas molecules as well as relevant molecules for porosimetry measurements ${ }^{154,222-224}$

\begin{tabular}{llcl}
\hline Species & $d_{\mathrm{k}} / \AA$ & $T_{\mathrm{b}} /{ }^{\circ} \mathrm{C}$ & $\mu$ \\
\hline $\mathrm{H}_{2}$ & 2.89 & -252 & 0.260 \\
$\mathrm{CO}_{2}$ & 3.30 & $-78^{a}$ & 2.139 \\
$\mathrm{CH}_{4}$ & 3.80 & -161 & 0.000 \\
$\mathrm{~N}_{2}$ & 3.64 & -196 & 0.697 \\
$\mathrm{O}_{2}$ & 3.46 & -182 & 0.155 \\
$\mathrm{Ar}$ & 3.40 & -186 & -
\end{tabular}

$d_{\mathrm{k}}=$ kinetic diameter, $T_{\mathrm{b}}=$ boiling point, $\mu=$ quadrupole moment. ${ }^{a}$ Sublimes.

the uptake density of gases under some standard adsorption conditions. For $\mathrm{H}_{2}$ this means that ultramicropores are the dominant pore structure for storage at atmospheric pressure, ${ }^{60}$ while optimum pore width is generally agreed upon to be $6 \AA^{212,216}$ Maximum hydrogen uptakes can be achieved by samples wherein the PSD is narrow, ${ }^{95}$ and centred around the optimum pore width; this is true at both cryogenic and ambient temperatures. ${ }^{212,228}$ There is also evidence that hydrogen and methane preferentially adsorb on carbon slit pores rather than cylindrical pores, ${ }^{229-231}$ which may give ACs an advantage over ZTCs.

To adsorb $\mathrm{CO}_{2}$ under ambient conditions it is generally agreed that the best carbonaceous sorbents have the majority of their pores smaller than $8 \AA$, and distributed narrowly ${ }^{62,63,96,97,219,232}$ (see Fig. 1) but slightly higher and lower limits have also been experimentally demonstrated. ${ }^{233,234}$ This limit decreases with decreasing pressure - at 0.1 bar, pores of $5 \AA$ have the biggest contribution to adsorption of $\mathrm{CO}_{2} \cdot{ }^{97,227}$ This is particularly applicable for post-combustion industrial capture applications wherein it is necessary to remove $\mathrm{CO}_{2}$ from a mixture of gases $\left(\begin{array}{lll}\sim 7 \% & \mathrm{~N}_{2}\end{array}\right)$. To achieve the selectivity necessary for such applications, adsorbents require ultramicropores as small as 3.5 A to prevent the ingress of larger molecules. ${ }^{235,236}$ At higher pressures the optimum pore size progressively increases into the supermicropore and small mesopore region. ${ }^{62,97,136,234,237}$ At such pressures, the PSD can broaden without harming overall uptake. ${ }^{66,126,227,238}$ In fact, high pressure $\mathrm{CO}_{2}$ capture can be harmed by excessive microporosity as overall pore volume needs to be maximized for optimal molecular packing. ${ }^{237}$

Determination of the optimum pore size for methane storage appears to have yielded less conclusive results than that for $\mathrm{H}_{2}$ and $\mathrm{CO}_{2}$. Computational estimates range from 11 to $15 \AA^{217,239,240}$ Through optimization experiments, Biloé et al. propose $15 \AA$ as the optimum, ${ }^{241}$ whereas other studies seem to suggest that optimal micropore width depends on whether the porous carbon is intended for gravimetric or volumetric storage.

\subsection{Surface area}

High pressure adsorption is much less dependent on pore size, and available surface area $\left(A_{\mathrm{BET}}\right)$ begins to dominate as a predictor of gas uptake capacity (Fig. $3 \mathrm{e}$ and f). In particular, Bénard and Chahine determined that cryogenic hydrogen storage capacity increases by approximately $1 \mathrm{wt} \%$ per $500 \mathrm{~m}^{2} \mathrm{~g}^{-1} \cdot^{242}$ However, the degree of influence of $A_{\mathrm{BET}}$ on $\mathrm{H}_{2}$ uptake posited in the eponymous Chahine rule has been recently disputed by Kusdhany and Lyth who found via a multivariate analysis that a $500 \mathrm{~m}^{2} \mathrm{~g}^{-1}$ increase in surface area corresponds to at most a $0.24 \mathrm{wt} \%$ increase in hydrogen uptake. ${ }^{243}$ Nonetheless high surface area remains an important factor in determining high pressure $\mathrm{H}_{2}$ storage capacity in carbons, with the best performing carbons possessing surface areas approaching $4000 \mathrm{~m}^{2} \mathrm{~g}^{-1} \cdot 82,98,178,220,238,244-247$ Similarly, in the case of $\mathrm{CO}_{2}$ and $\mathrm{CH}_{4}$ capture and storage, increased surface area is generally associated with improved gravimetric uptake. ${ }^{14,35,131,132,194,248-255}$ However, depending on the prevailing pressure, $\mathrm{CO}_{2}$ capture is much less dependent on surface area, and having pores of the appropriate size is more important. ${ }^{132,244,252,256}$ In fact recent work by Jing Cui et al. suggests that excessive volumetric surface area results in poor selectivity of $\mathrm{CO}_{2}$ over $\mathrm{N}_{2}$, a metric which is vital in many industrial applications. ${ }^{257}$ Furthermore, gravimetric surface area is becoming a less interesting variable for $\mathrm{CH}_{4}$ storage because it does not correlate well to volumetric capacity. ${ }^{18,35,258}$ As such, metrics like packing density and volumetric surface area (surface area density, see Fig. 1) are often cited in lieu of or as well as the traditional gravimetric value. ${ }^{35,194,259}$

\subsection{Pore volume}

Pore volume generally correlates to surface area, and thus increases in pore volume are typically associated with increases in gas adsorption capacity. Of course, the strength of the relationship between pore volume and surface area is affected by the size of the pores in question, i.e. an ultramicropore will contribute much less pore volume than a mesopore of identical 

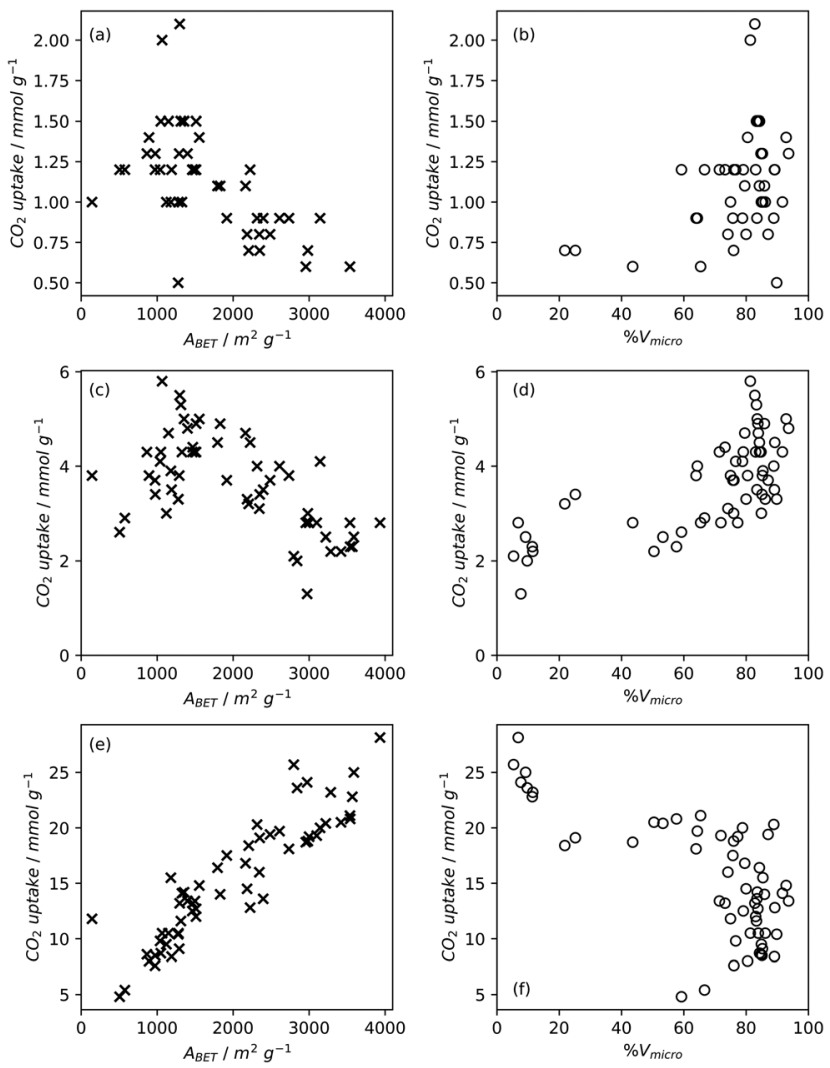

Fig. 3 Trends in BET surface area and percentage micropore volume with $\mathrm{CO}_{2}$ uptake capacity of carbons $\mathrm{s}^{78,80,81,135,237,238,244,248}$ at 0.15 bar (a) and (b), 1 bar (c) and (d), and 20 bar (e) and (f).

surface area. ${ }^{20,234,260}$ If a sample is mostly microporous and has a high total pore volume, this indicates that there are lots of or very deep micropores within the sample. Such a sample is advantageous for small molecule adsorption, especially at lower pressures. As such, (percentage) micropore volume rather than total pore volume is likely a better predictor for $\mathrm{H}_{2}, \mathrm{CO}_{2}$ or $\mathrm{CH}_{4}$ uptake (Fig. 2-4). ${ }^{14,18,20,34,68,257,261}$

\subsection{Measuring porosity}

Unlike for crystalline materials, the porosity of ZTCs and ACs cannot be easily determined using diffractive techniques such as XRD. Additionally, due to the size of pores needed for small molecule sorption, use of electron microscopy is not a particularly accurate technique for determining porosity. Thus, sorptometric porosimetry remains the main method for determining specific surface area, pore volume and pore size of carbons.

3.4.1. Choice of adsorptive. Sorptometry of carbons is typically performed by measuring nitrogen isotherms at $-196{ }^{\circ} \mathrm{C}$. While subcritical argon is recommended as the best adsorptive by the IUPAC, ${ }^{218}$ such measurements are uncommon in the literature due to its impracticality and relatively highcost of such measurements with respect to using nitrogen. Unfortunately, cryogenic nitrogen isotherms are the source of two errors in pore width measurement. Firstly, nitrogen does
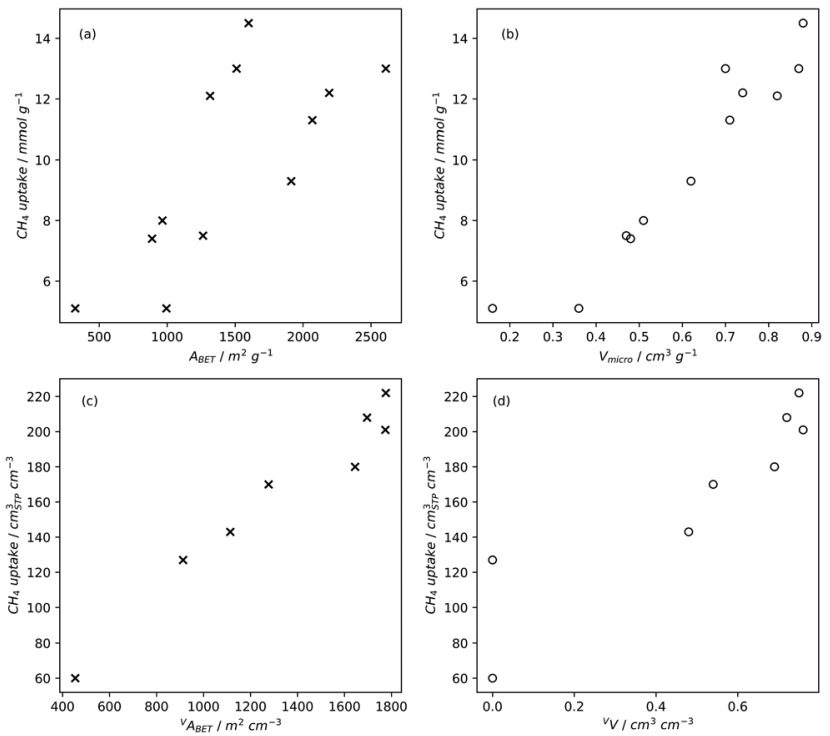

Fig. 4 Trends in $\mathrm{CH}_{4}$ uptake with gravimetric (a) and (b) and volumetric (c) and (d) porosity of carbons $35,131,258$ at 35 bar and $25^{\circ} \mathrm{C}$.

not readily diffuse into so-called ultramicropores (of width $<7 \AA$ ). This means that in order to attempt to measure these pores, extremely low relative pressures must be used, on the order of $\sim 10^{-8}$. However, under these conditions diffusion occurs extremely slowly, in fact equilibrium may not ever be achieved. ${ }^{225,262}$ As a result, many studies have opted out of using low pressure nitrogen isotherms, but instead probe ultramicropores using $\mathrm{CO}_{2}$ isotherms at $0{ }^{\circ} \mathrm{C} .{ }^{62,102,226,263-267}$ $\mathrm{CO}_{2}$ isotherms do however have an upper detectable pore size limit under these conditions as condensation will not be achieved. Thus, the combination of these two isotherms can be used to produce a better picture of micropore sizes above 4 A.

Secondly, nitrogen's relatively high quadrupole moment ${ }^{224}$ can confound measurements on samples containing polar moieties as is the case for many activated carbons. Polar groups affect the orientation of nitrogen with respect to the surface this results in the actual cross-sectional area of the molecule differing to that which is used in calculations of textural parameters such as $A_{\mathrm{BET}}$. This is even more problematic for $\mathrm{CO}_{2}$ as it is more polar than $\mathrm{N}_{2} \cdot{ }^{224,268}$ As such, dual gas adsorption techniques may also employ $\mathrm{O}_{2}$ and $\mathrm{H}_{2}$ (at $-196{ }^{\circ} \mathrm{C}$ ) which both have lower quadrupole moments than $\mathrm{N}_{2} \cdot{ }^{225,268,269}$ $\mathrm{H}_{2}$ has the added advantage of being smaller than $\mathrm{CO}_{2}$ thus improving the lower pore size limit to $\sim 3 \AA^{225}$

\subsubsection{Calculations}

Classical. Historically, measures of porosity were determined via individual manipulations and/or calculations from the raw isotherm.

(i) Surface area: Stephen Brunauer, Paul Hugh Emmett, and Edward Teller expanded Langmuir theory to account for multilayer adsorption, which occurs at higher pressures and temperatures. The eponymous BET surface area, $A_{\mathrm{BET}}$, is calculated by first determining the total quantity of gas adsorbed, $Q$, and from this calculating $Q_{\mathrm{m}}$, the quantity of gas in the monolayer 
using the following equation;

$$
\frac{1}{Q\left(\frac{P_{0}}{P}-1\right)}=\frac{c-1}{Q_{\mathrm{m}} c}\left(\frac{P}{P_{0}}\right)+\frac{1}{Q_{\mathrm{m}} c}
$$

where the BET constant, $c$, is derived from the heat of adsorption of the first and subsequent layers $\left(E_{1}\right.$ and $\left.E_{\mathrm{L}}\right)$;

$$
c=\mathrm{e}^{\frac{E_{1}-E_{\mathrm{L}}}{R T}}
$$

A measured isotherm can be transformed in accordance with the BET equation allowing for the determination of $Q_{\mathrm{m}}$ from a linear portion of the plot, selected according to the Rouquerol criteria. ${ }^{270,271}$ Thus $A_{\mathrm{BET}}$ is determined using the adsorption cross-section, $\sigma$, and mass of the adsorbate, $a$;

$$
A_{\mathrm{BET}}=\frac{Q_{\mathrm{m}} N_{\mathrm{A}} \sigma}{a}
$$

Despite its ubiquity, the theoretical backing of $A_{\mathrm{BET}}$ does not robustly describe the surface area of all materials, particularly in the case of materials having very small pores as so-called multilayer adsorption is not relevant here. ${ }^{218,271}$ In addition, the model does not account for surface chemical or energetic heterogeneity, and as such $\sigma$ may differ at different points on the surface. ${ }^{218,225,272} \mathrm{As}$ a result $A_{\mathrm{BET}}$ should not be considered a 'true' value for the surface area of porous carbons. Nevertheless if applied consistently and correctly, (i.e. selecting the relative pressure range as ascribed by the aforementioned Rouquerol criteria), ${ }^{218,271} A_{\mathrm{BET}}$ provides the 'apparent' surface area for microporous materials, which is a useful metric for comparing the porosity of different, related samples. This is in contrast to the much simpler typical criteria used to select the pressure region for determination of $A_{\mathrm{BET}}$ in mesoporous, macroporous or nonporous materials, wherein the range is typically between 0.05 and 0.30 .

It should be noted however that manual application of the Rouquerol criteria can be extremely inconsistent when applied by different people. In a round-robin study, the FairenRodriguez group found that the manually determined $A_{\mathrm{BET}}$ from the same isotherm could differ by more than $7000 \mathrm{~m}^{2} \mathrm{~g}^{-1}$. Furthermore, even when applied correctly the Rouquerol method can yield multiple acceptable pressure regions for an isotherm. They therefore propose an algorithmic approach to determine of the optimal Rouquerol range and thus the valid BET area. ${ }^{273}$

(ii) Pore volume: is typically measured using the quantity of gas adsorbed at the isothermal plateau and at relative pressure approaching 1 , as by this point the pores are considered to be fully filled by the adsorbate. As this method only uses one point on the isotherm, it is known as the single-point pore volume calculation. ${ }^{218}$ This method is not applicable to all isotherms, as some do not exhibit a plateau.

(iii) Microporosity: there are various classical methods used for this, the first of these being the t-plot method which relies upon comparison of the experimental isotherm with that of a standard adsorbent under the same analytical conditions. ${ }^{274}$ This of course relies on an appropriate standard, which is not always available. Furthermore this method may give inaccurate micropore volumes for samples that contain significant mesoporosity, ${ }^{275}$ in some cases yielding negative values for microporosity. ${ }^{276}$ Further developments include the $\alpha_{\text {s }}$, DubininAstakhov (DA) and Dubinin-Radushkevich (DR) plots. ${ }^{274,277}$ These methods utilise a transformation of the isotherm to yield a roughly linear plot. The slopes and intercepts of such plots can then be used to calculate micropore volume and surface area.

(iv) Pore size: methods are available for determination of a pore size distribution such as $\mathrm{H}-\mathrm{K}$ (Horváth-Kawazoe) and $\mathrm{BJH}$ (Barrett, Joyner and Halenda) from an $\mathrm{N}_{2}$ isotherm in the micropore and mesopore region, respectively. The former relies on the assumption that pores of some width fill at a certain relative pressure, which in turn is calculated using molecular potentials. The latter method uses the isotherm's desorption branch to relate the amount of $\mathrm{N}_{2}$ removed from pores at decreasing relative pressure to pore width. ${ }^{278,279}$ Whatever the method, PSDs can be displayed in cumulative or differential form and according to either surface area or pore volume. Once the PSD is achieved, determination of an average pore width is trivial.

Density functional theory. Classical models for pore structure determination rely on parameters including (but not limited to) the monolayer capacity of the adsorbent, as well as the adsorbate-adsorbent interaction. Additionally, they make use of potentially false assumptions such as that the adsorbate behaves as a two-dimensional ideal gas (in the case of the Horvath-Kawazoe model). Conversely, Density Functional Theory (DFT), when applied to porosity, makes use of statistical modelling of adsorbate-adsorbate and adsorbate-adsorbent interactions specific to a system determined by pore size, pore geometry, nature of the adsorptive and temperature. A set of theoretical isotherms is generated according to the specific variables of the system under examination, where each individual, theoretical isotherm is calculated for an idealized adsorbent having a single pore width. This library of calculated isotherms is known as the kernel, $N\left(\frac{P}{P_{0}}, W\right)$ which can be used in conjunction with the experimental isotherm, $N\left(\frac{P}{P_{0}}\right)$ to yield a pore size distribution as a function of pore width, $f(W) ;{ }^{274}$

$$
N\left(\frac{P}{P_{0}}\right)=\int_{W_{\min }}^{W_{\max }} N\left(\frac{P}{P_{0}}, W\right) f(W) \mathrm{d} W
$$

This data can be displayed in terms of differential or cumulative pore volume and surface area, and as such can be used to determine textural quantities traditionally calculated via classical methods. ${ }^{215,266}$ Recent reports indicate that gas uptake may be better predicted using porosity determined according to DFT rather than classical methods. ${ }^{280,281}$ DFT methods have also been employed in recent years to combine isotherms determined using two separate gases to yield a single PSD. ${ }^{91,225}$

It is useful to compare measures of porosity derived using DFT methods to those using classical methods. In terms of pore volume, Jagiello et al. reported that both total and micropore 
volume of a set of biochars and activated carbons as determined using the single-point and DR methods respectively, were essentially the same as those found using DFT. ${ }^{91}$ This was shown to also be true for micropore volumes. ${ }^{282}$ VillarroelRocha et al. found broad agreement between values of micropore volume in microporous materials derived using the DR, t-plot, $\alpha_{\mathrm{S}}$ and DFT methods. ${ }^{275}$ However, this is not true in the application of these methods to all isotherms; DFT and t-plot methods show greater disagreement the further the isotherm deviates from type-I. ${ }^{275,276}$

\subsection{Grain density}

While gravimetric measures of porosity have historically been the metric associated with gas uptake increasingly, high volumetric capacity is desired in applications such as methane storage, ${ }^{127,260,283}$ as well as $\mathrm{CO}_{2}$ capture. ${ }^{174,284,285}$ Various studies have shown that grain density is a good predictor of $\mathrm{H}_{2}, \mathrm{CH}_{4}$ and $\mathrm{CO}_{2}$ capacity, provided that this is balanced with appropriate pore size as well as high surface area and pore volume. $^{35,81,143,178,182,194,255,284,286}$ Grain density, $d$ may be calculated according to

$$
d=\left(\frac{1}{\rho_{\mathrm{s}}}+V_{\mathrm{T}}\right)^{-1}
$$

where $\rho_{\mathrm{s}}$ is the skeletal density determined via helium pycnometry and $V_{\mathrm{T}}$ is the total pore volume. ${ }^{35}$ Alternatively it can be measured directly by packing the sample at high pressure. ${ }^{127}$ Determination of grain density allows for the derivation of volumetric equivalents to surface area and pore volume, which are typically calculated gravimetrically. These can be used as further metrics to assess volumetric gas uptake (see Fig. 4).

\section{Controlling porosity}

While the achievement of reasonable porosity in carbons for small gas molecule adsorption is relatively well established, various methods for fine control over various textural parameters are under constant development. Of particular recent interest in the literature are methods to improve volumetric as opposed to gravimetric porosity so as to optimise volumetric capacity for applications such as on-board storage.

\subsection{Activated carbons}

4.1.1. Choice of activating agent. $\mathrm{KOH}$ is the primary reagent used for synthesis of activated carbons intended for physisorption of small molecules as it yields superior carbons with high surface area and pore volume, a high degree of microporosity and tuneable PSD. ${ }^{20,79,127,220,233,249,287-289}$ Nonetheless, physical activating agents such as $\mathrm{CO}_{2}$ and steam, ${ }^{77,249,260,288,290}$ as well as other 'traditional' chemical agents such as $\mathrm{ZnCl}_{2}, \mathrm{H}_{3} \mathrm{PO}_{4}$ and $\mathrm{NaOH}$ continue to be explored. ${ }^{152,252,287-289,291,292}$ A summary of textural properties of carbons derived using a variety of activating agents is presented in Table 2. Recently Chao Ge et al. have produced moderate surface area (up to $865 \mathrm{~m}^{2} \mathrm{~g}^{-1}$ ) carbons by $\mathrm{CO}_{2}$ activation of polyurethane films at $1000{ }^{\circ} \mathrm{C}$, with $\mathrm{CO}_{2}$ capacity of $c a .3 \mathrm{mmol} \mathrm{g}^{-1}$ at 1 bar and $0{ }^{\circ} \mathrm{C}$. It should be noted however that this uptake is not realistic, as post-combustion capture is unlikely to take place at $0{ }^{\circ} \mathrm{C}$, so we can expect significantly less uptake at more realistic temperatures $\left(>25{ }^{\circ} \mathrm{C}\right) .{ }^{293}$ In addition, this uptake is likely significantly improved by the high $\mathrm{N}$-content of this carbon. The uptake of the $\mathrm{CO}_{2}$-activated carbon was dwarfed by $\mathrm{NaOH}-$ and $\mathrm{KOH}$-activated samples reported in the same work, which have superior microporosity. ${ }^{288}$ While $\mathrm{KOH}$ can produce extensive microporosity, for some applications this may not be as relevant; Yueqin Song et al. produced activated carbons from coconut shell charcoal using both $\mathrm{KOH}$ and $\mathrm{H}_{3} \mathrm{PO}_{4}$ as activating agents. Despite the $\mathrm{KOH}-$ activated sample having a surface area triple that of its $\mathrm{H}_{3} \mathrm{PO}_{4}$ activated counterpart, their gravimetric methane capacity at 1 bar and $10{ }^{\circ} \mathrm{C}$ was nearly identical at 4.1 and $4.0 \mathrm{mg} \mathrm{g}^{-1}$ respectively. ${ }^{287}$ The narrow PSD associated with $\mathrm{KOH}$-activation at $\mathrm{KOH} /$ precursor mass ratio $<2$ can also be achieved using $\mathrm{ZnCl}_{2}$, however surface area and pore volume of such samples tend to be relatively low. ${ }^{112,152}$ Indeed, the ultrahigh surface areas accompanied by extreme microporosity required for $\mathrm{H}_{2}$ storage at high pressures ( $>40$ bar) can only be readily achieved by activation with $\mathrm{KOH}$. Conversely, the multiplicity of $\mathrm{CO}_{2}$ adsorption applications under different pressure and temperature conditions means that a greater variety of textural characteristics are useful for $\mathrm{CO}_{2}$ capture on activated carbons. ${ }^{61,220,221,237,294}$ Thus, when 'alternative' chemical activating agents are reported that yield lower surface area materials, the suggested application is typically some form of $\mathrm{CO}_{2}$ capture

Table 2 Porosity of recently reported carbons derived using a variety of porogens, and gravimetric gas uptakes where available

\begin{tabular}{|c|c|c|c|c|c|c|c|}
\hline Porogen & Precursor $^{a}$ & $A_{\mathrm{BET}}^{b}$ & $V_{\mathrm{t}}^{c}$ & $\% V_{\text {mic }}{ }^{d}$ & $S^{e}$ & $U^{f}$ & Ref. \\
\hline $\mathrm{CO}_{2}$ & Graphite oxide & 908 & 3.08 & 3 & $\mathrm{CO}_{2}(1,0)$ & 1.6 & 249 \\
\hline $\mathrm{KOH}$ & Cigarette butts ${ }^{g}$ & 4310 & 2.09 & 82 & $\mathrm{H}_{2}(20,-196)$ & 9.4 & 82 \\
\hline $\mathrm{K}_{2} \mathrm{CO}_{3}$ & Polyacrylonitrile & 1250 & 0.64 & 89 & $\mathrm{CO}_{2}(1,30)$ & 2.4 & 252 \\
\hline $\mathrm{KHCO}_{3}$ & Glucose $^{g}$ & 2210 & 0.97 & 84 & & & 138 \\
\hline Potassium oxalate & Sawdust $^{g}$ & 1470 & 0.71 & 73 & $\mathrm{CO}_{2}(1,25)$ & 4.4 & 135 \\
\hline $\mathrm{NaOH}$ & Polyacrylonitrile & 1020 & 0.57 & 89 & $\mathrm{CO}_{2}(1,30)$ & 2.2 & 252 \\
\hline $\mathrm{NaNH}_{2}$ & Polyacrylonitrile & 833 & 0.36 & 94 & $\mathrm{CO}_{2}(1,30)$ & 1.8 & 252 \\
\hline $\mathrm{H}_{3} \mathrm{PO}_{4}$ & Coconut shell & 304 & & & $\mathrm{CH}_{4}(1,10)$ & 0.3 & 287 \\
\hline
\end{tabular}

${ }^{a}$ Precursor description. ${ }^{b}$ BET surface area $\left(\mathrm{m}^{2} \mathrm{~g}^{-1}\right) .{ }^{c}$ Total pore volume $\left(\mathrm{cm}^{3} \mathrm{~g}^{-1}\right) .{ }^{d}$ Percent microporosity by volume. ${ }^{e}$ Adsorbate measured (values in brackets are pressure (bar) followed by temperature $\left({ }^{\circ} \mathrm{C}\right)$ ). ${ }^{f}$ Uptake in mmol g ${ }^{-1}$ except for $\mathrm{H}_{2}$, which is wt $\%$. ${ }^{g}$ Precursor was converted to hydrochar prior to activation. 
(see Table 2). ${ }^{75,135,232,252,288}$ As an example, a recent paper by Weiwei Shi and co-workers found that activating ammonium citrate with $\mathrm{CuCl}_{2}$ generates carbons were with hierarchical pore structure, albeit almost exclusively (up to 94\%) in the micropore region. The authors' hypothesis is that coordination between $\mathrm{Cu}^{2+}$ ions and organic moieties is one of the driving forces for porosity development. Reasonable $\mathrm{CO}_{2}$ capacity of $4.21 \mathrm{mmol} \mathrm{g}^{-1}$ was achieved at 1 bar and $25{ }^{\circ} \mathrm{C} .{ }^{295}$

The success of group 1 metal hydroxides as activating agents for highly microporous carbons has led to the exploitation of other hydroxides, as well as salts of potassium and sodium as porogens. $^{232,252,288,296,297}$ Theoretically a gentler activating agent, $\mathrm{Ca}(\mathrm{OH})_{2}$-activation yields carbons with much lower surface areas and a lower degree of microporosity than $\mathrm{KOH}$ under identical conditions. ${ }^{288}$ Taylor found that careful selection of conditions may produce carbons with pore volumes exceeding $1 \mathrm{~cm}^{3} \mathrm{~g}^{-1}$, with the majority of this coming from mesopores. ${ }^{296}$ Although microporosity is low, activation at $800{ }^{\circ} \mathrm{C}$ yields carbons whose micropores are dominated by pores around $8 \AA$, thus achieving moderate $\mathrm{CO}_{2}$ capacity of up to $2.3 \mathrm{mmol} \mathrm{g}^{-1}$ at 1 bar and $25{ }^{\circ}$ C. $^{296}$ Similarly, Singh et al. reported that the activation of polyacrylonitrile with $\mathrm{NaNH}_{2}$ yields carbons with low overall porosity development, but a higher concentration of pores centred at $7 \AA$ when compared to carbons activated with $\mathrm{NaOH}$ under similar conditions. This indicates that when using $\mathrm{NaNH}_{2}$ as an activating agent much of the porosity is likely formed via $\mathrm{Na}$ intercalation, rather than redox reactions - in contrast to what happen with $\mathrm{NaOH}$ as activating agent. ${ }^{252}$

While $\mathrm{KOH}$ has been identified as a uniquely superior activating agent, its corrosive nature qualifies it as an aggressive reagent in activated carbon synthesis, thus resulting in low yields. As the majority of the microporosity comes about via the intercalation of potassium ions into graphitic layers as opposed to corrosive action of the hydroxide counterion, gentler anions such as carbonate, ${ }^{232,298}$ and bicarbonate, ${ }^{138,299}$ have been shown to give improved yields, resulting in high surface area carbons with tuneable porosity. For example, Sevilla and Fuertes produced $\mathrm{KHCO}_{3}$-activated carbons from glucose hydrochar with surface areas of $2000 \mathrm{~m}^{2} \mathrm{~g}^{-1}$ with more than $80 \%$ microporosity. Porosity development is lower than that for an equivalent amount of $\mathrm{KOH}$ under similar conditions because the initial pore formation process - the oxidation of $\mathrm{C}$ by $\mathrm{K}_{2} \mathrm{CO}_{3}$ - requires temperatures in excess of $700{ }^{\circ} \mathrm{C}$, while $\mathrm{KOH}$ can oxidise $\mathrm{C}$ at much lower temperatures. ${ }^{138}$ On the other hand, Xia and co-workers use of an acetate counterion has shown that a contributing factor to pore formation may be hydrogen bonding between polar moieties within the biomass and the activating agents. ${ }^{297}$

Another promising 'gentle' potassium activating agent is potassium oxalate (PO). ${ }^{131,135-137,300,301}$ The activation mechanism proceeds principally via gasification of $\mathrm{K}_{2} \mathrm{CO}_{3}$ at or below $800{ }^{\circ} \mathrm{C}$, resulting in carbons that are almost exclusively microporous. Therefore activating with PO allows a high degree of control over sample porosity - Aljumialy and Mokaya found that pore volume of sawdust-derived carbons could be reliably increased within the micropore region by increasing activation temperature. Interestingly this improvement in overall porosity had little effect on pore sizes. When the activation temperature is increased to $900{ }^{\circ} \mathrm{C}$, oxidative etching of the carbon surface begins, ${ }^{135,136}$ which results in mesopore formation without the collapse of the previously formed micropores, producing carbons with a hierarchical pore network optimised for moderate pressure (20 bar) $\mathrm{CO}_{2}$ storage $\left(18 \mathrm{mmol} \mathrm{g}^{-1}\right.$ excess uptake). The highly microporous ( $>90 \%$ microporosity) carbons produced at lower temperatures achieve $\mathrm{CO}_{2}$ capacity of $4.3 \mathrm{mmol} \mathrm{g}^{-1}$ at room temperature and ambient pressure. ${ }^{135}$ Lee et al. achieved similarly high degrees of microporosity (approaching 100\%) in the PO activation of carbonized corn husks (CCH). Quite unusually, increasing quantities of PO lead to greater development of ultramicropores. Methane capacity was optimised $\left(7.75 \mathrm{mmol} \mathrm{g}^{-1}\right.$ at $35 \mathrm{bar}$ and $\left.25^{\circ} \mathrm{C}\right)$ at $\mathrm{PO} / \mathrm{CCH}$ ratio of 3 as a result of highest surface area as well as hierarchical pore structure including ultramicropores. ${ }^{131}$

Mixing method. Chemical activating agents may be combined with the precursor material either through physical mixing $^{35,135,255,302}$ or by impregnation with a dissolved agent. $^{75,288,290,295,303}$ The latter technique, so-called solution impregnation, is followed by a drying step to remove the solvent prior to activation. The perceived advantage of solution impregnation over solid mixing is that the activating agent is more evenly distributed, thus resulting in more consistent porosity throughout the material. Nevertheless, PSDs of carbons derived using the physical mixing technique show narrow PSDs indicating that an impregnation and drying step may not strictly be necessary. ${ }^{80,82,135}$ There is, unfortunately, a dearth of literature comparing the porosity of carbons derived using the two techniques. However, in 2018 Boujibar et al. reported activated carbons synthesised using $\mathrm{KOH}$ and $\mathrm{NaOH}$ via both solution impregnation and physical mixing. In terms of surface area, the $\mathrm{KOH}$-activated samples showed improvements of $20 \%$ when physical mixing was employed but these gains reduced the proportion of microporosity. Conversely, surface area of $\mathrm{NaOH}-$ activated samples were $25 \%$ greater using solution impregnation over physical mixing, though the former samples had a much broader PSD. Despite the differences in textural properties attained through these two mixing techniques, $\mathrm{CO}_{2}$ uptake at $25{ }^{\circ} \mathrm{C}$ and 1 bar does not significantly differ between the two sample sets, implying that both impregnation and solid mixing can be effectively used to balance overall porosity development and level of microporosity for gas adsorption. ${ }^{292}$

Combined activating agents. While chemical activating agents provide highly microporous samples which are suited to $\mathrm{H}_{2}$ storage and low pressure $\mathrm{CO}_{2}$ capture, other applications such as high pressure $\mathrm{CO}_{2}$ capture require so-called hierarchical or multimodal pore structures wherein most or all microporosity is retained but further porosity is generated in the mesopore region. Caturla et al. achieved this in 1991 by subjecting a $\mathrm{ZnCl}_{2}$-activated carbon to physical activation using $\mathrm{CO}_{2}{ }^{112}$ Using both a chemical and physical activating agent has become known as physicochemical activation. Since then other 
researchers have produced activated carbons via a simultaneous physicochemical method, wherein during the pyrolysis of a mixture of precursor and chemical activating agent the flow of inert gas is interrupted with a physical activating agent. $^{152,287,304,305}$ In fact, $\mathrm{Hu}$ and Srinivasan reported that simultaneous physicochemical activation using $\mathrm{ZnCl}_{2}$ and $\mathrm{CO}_{2}$ is more effective for formation of mesopores than an equivalent sequential activation. ${ }^{304} \mathrm{KOH}$ and $\mathrm{H}_{3} \mathrm{PO}_{4}$ have also been used as the chemical porogen in conjunction with $\mathrm{CO}_{2}$ although it appears that using $\mathrm{KOH}$ makes the material more resistant to mesopore development. ${ }^{305,306}$ Table 3 gives examples of the porosity of carbons derived through single and two step-activations.

Physicochemical activation is not limited to broadening of PSDs; for example Song et al. explored the sequential physicochemical activation of coconut shell charcoal using $\mathrm{H}_{3} \mathrm{PO}_{4}$ and steam and found that steam treatment at $800{ }^{\circ} \mathrm{C}$ produced carbons with twice the surface area of those activated with $\mathrm{H}_{3} \mathrm{PO}_{4}$ alone. In contrast to earlier carbons produced using $\mathrm{ZnCl}_{2}$ and $\mathrm{CO}_{2}$, the majority of new porosity development was in the micropore region, with $80 \%$ of surface area from pores of width 4.5-6.5 A. This sample achieved 58\% higher gravimetric $\mathrm{CH}_{4}$ uptake at 1 bar and $10{ }^{\circ} \mathrm{C}$ compared to a conventionally activated equivalent. ${ }^{287}$ Adlak et al. reported similar improvements in both overall surface area and microporosity for carbons activated using $\mathrm{KOH}$ and steam simultaneously. This could be a result of the dissolution of $\mathrm{K}$ compounds in steam, which results in greater mobility of the activating agent through the sample and thus further activation via intercalation. ${ }^{290}$

The porosity of carbon can also be modulated by adding a so-called mediator to the precursor-activating agent mixture. The mediator is a species that is not in itself an activating agent, but produces activating species as it breaks down during pyrolysis, which can then work in conjunction with the activating agent to produce multimodal porosity. An early example of a mediator is the use of melamine by Fuertes and Sevilla in the $\mathrm{KOH}$-activation of hydrochars. Samples synthesised using melamine had higher surface areas than their conventionally activated counterparts, which came about through the development of mesopores. These mesopores purportedly originate from gasification by volatile nitrogen compounds released upon the decomposition of melamine. ${ }^{307}$ Indeed, there are other notable instances of volatiles from nitrogenous compounds having an activating effect. ${ }^{221,308}$ Further work revealed that surface areas above $3200 \mathrm{~m}^{2} \mathrm{~g}^{-1}$ could be achieved by this method, with optimal porosity for cryogenic $\mathrm{H}_{2}$ storage at 20 bar, and room temperature $\mathrm{CO}_{2}$ capture at 40 bar, achieving uptakes of $7 \mathrm{wt} \%$ and $21 \mathrm{mmol} \mathrm{g}^{-1}$, respectively. ${ }^{244}$ By swapping $\mathrm{KOH}$ for the gentler $\mathrm{PO}, \mathrm{CO}_{2}$ uptake at 40 bar was improved to almost $40 \mathrm{mmol} \mathrm{g}^{-1}$ due to a broad, continuous PSD spanning the ultramicropore and small mesopore region. ${ }^{136}$ More recently $\mathrm{Hu}$ et al. reported the use of sodium alginate as a mediator in conjunction with $\mathrm{KOH}$ to prevent the over-activation of carbons derived from a variety of biochars. ${ }^{309}$ The pyrolysis of sodium alginate had previously been shown to produce non-porous carbons. $^{308}$ On pyrolysis the mediator broke down to produce $\mathrm{Na}_{2} \mathrm{O}$ which appears to have restricted porosity development and limited the PSD to the micropore region accompanied by further development of ultramicropores. As a result, $\mathrm{H}_{2}$ storage capacity at 1 bar and $-196{ }^{\circ} \mathrm{C}$ was improved by up to $87 \%$ from $1.37 \mathrm{wt} \%$ to $2.56 \mathrm{wt} \%$. $^{309}$

Self-activation. In recent years, research interest has turned to precursors that can develop porosity via pyrolysis without the

Table 3 Comparison of porosity and gas uptake of activated carbons derived via activation in one or two activation steps

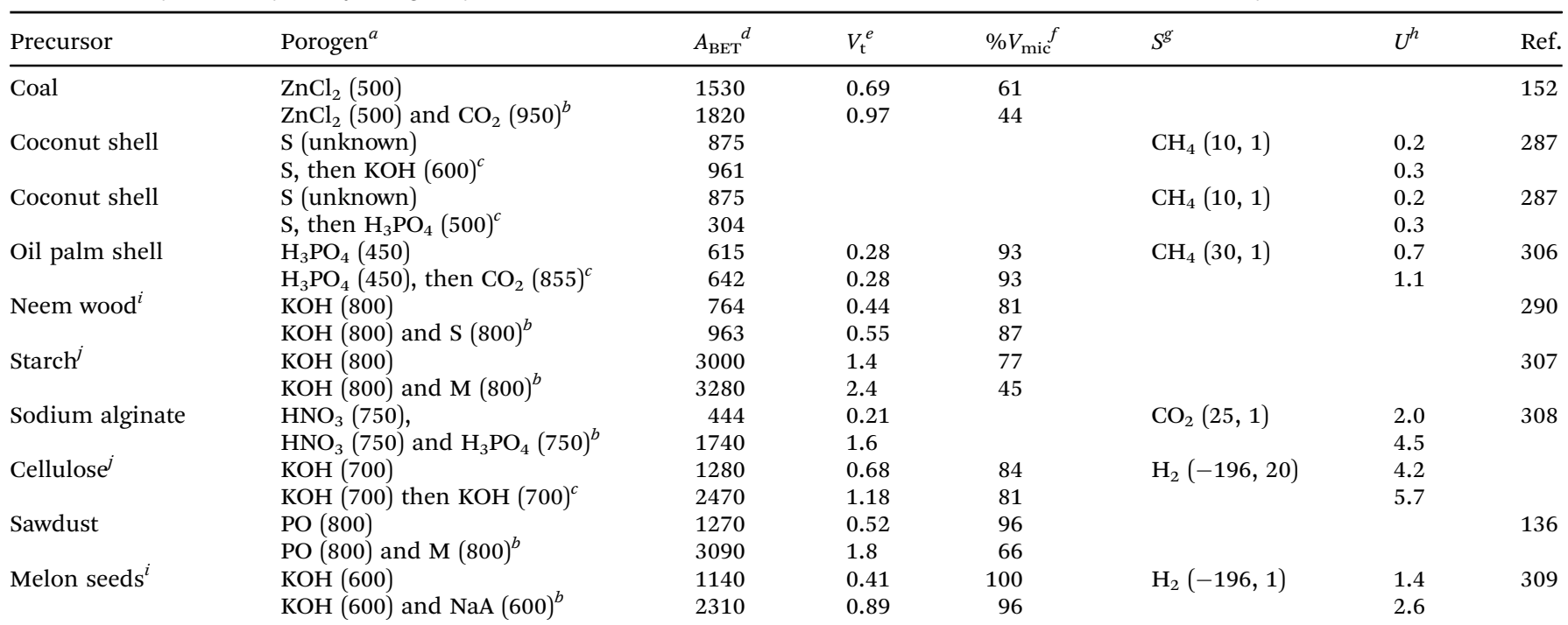

${ }^{a}$ First and second steps. Activation temperature $\left({ }^{\circ} \mathrm{C}\right)$ in parenthesis, $\mathrm{S}=$ steam, $\mathrm{M}=$ melamine, $\mathrm{PO}=$ potassium oxalate, NaA $=$ sodium alginate. ${ }^{b}$ Simultaneous activation. ${ }^{c}$ Sequential activation. ${ }^{d}$ BET surface area $\left(\mathrm{m}^{2} \mathrm{~g}^{-1}\right) .{ }^{e}$ Total pore volume $\left(\mathrm{cm}^{3} \mathrm{~g}^{-1}\right) .{ }^{f}$ Percentage microporosity by volume. ${ }^{g}$ Adsorbate gas $\left(\mathrm{CH}_{4}, \mathrm{CO}_{2}\right.$ or $\left.\mathrm{H}_{2}\right)$; values in parenthesis are measurement temperature $\left({ }^{\circ} \mathrm{C}\right)$ and pressure (bar), respectively. ${ }^{h}$ Gravimetric uptake in $\mathrm{mmol} \mathrm{g}^{-1}$, except for $\mathrm{H}_{2}$, which is $\mathrm{wt} \% .{ }^{i}$ Precursor was pyrolysed before porogenesis. ${ }^{j}$ Precursor was hydrothermally carbonised before porogenesis. 
assistance of an external activating agent. As previously mentioned, so-called biochar is derived through physical selfactivation of biomass to produce microporous carbons, ${ }^{89-91}$ through the release of oxidising gases such as $\mathrm{CO}_{2}$ and $\mathrm{H}_{2} \mathrm{O}$ upon biomass pyrolysis. ${ }^{310,311}$ Under typical conditions, the bulk of these oxidising gases are removed from the sample due to a flow of $\mathrm{N}_{2}$ or Ar before they can develop significant porosity. Xia and Shi found that long, harsh pyrolysis of kenaf core in a closed system allowed the oxidising gases to react more with the carbonised biomass to form pores, resulting in mesoporous carbons with surface areas approaching $2500 \mathrm{~m}^{2} \mathrm{~g}^{-1}$. Carbons with hierarchical pore structures were produced when temperature and dwell time were limited to $1000{ }^{\circ} \mathrm{C}$ and $10 \mathrm{~h}$ respectively. ${ }^{312}$

Precursors or additives with high nitrogen contents are often employed to produce $\mathrm{N}$-doped carbons for use in $\mathrm{CO}_{2}$ capture. However, nitrogen also has a part to play in porosity development in the mesopore region. Sevilla et al. found that polypyrrole-derived carbons gave higher than expected surface area for the activation conditions. ${ }^{126}$ Later work confirmed that by increasing the $\mathrm{N}$ concentration by use of an additive, the porosity of microporous carbons could be extended into the mesopore region, resulting in higher $\mathrm{H}_{2}$ and $\mathrm{CO}_{2}$ storage capacity. This effect is presumed to come about due to the gasification of the carbonaceous structure by volatile N-compounds. ${ }^{244,307}$ Similar effects have also been reported by Ariharan et al. for precursors containing phosphorous. ${ }^{313,314}$

Self-activation may also have had a part to play in the unusual temperature-porosity relationship of a series of cigarette butt-derived $\mathrm{KOH}$-activated carbons. It is supposed that the unexpectedly high surface area $\left(4300 \mathrm{~m}^{2} \mathrm{~g}^{-1}\right)$ of highly microporous sample activated at $600{ }^{\circ} \mathrm{C}$ may be a result of metal contaminants within the cigarette butt that assist $\mathrm{KOH}$ in the activation process. Such textural properties resulted in unprecedented hydrogen storage capacity of $8.1 \mathrm{wt} \%$ at $-196{ }^{\circ} \mathrm{C}$ and 20 bar. $^{82}$ This idea of activation by contaminants is supported by a 2018 study by Longxin Li et al. wherein carbons produced via the simultaneous physicochemical activation of demineralised coal achieved lower surface areas than and equivalent carbon from untreated coal. ${ }^{152}$

Organic salt carbonisation. Organic salts are an interesting class of so-called self-activating precursors for activated carbon production. To achieve self-activation, the cation must be a metal that can take part in chemical activation. Furthermore, the anion must be both sufficiently rich in carbon, and stable enough that it does not fully degrade before its cation can cause it to undergo activation. For example, while PO is interesting as a so-called gentle porogen, the oxalate $\left(\mathrm{C}_{2} \mathrm{O}_{4}{ }^{2-}\right)$ anion degrades to $\mathrm{CO}_{3}{ }^{2-}$ before activation can be achieved, meaning that no residual carbon remains. ${ }^{133}$ More bulky precursors such as $\mathrm{K}$, $\mathrm{Na}, \mathrm{Ca}, \mathrm{Mg}, \mathrm{Fe}$, and $\mathrm{Zn}$ salts of citric acid have been successfully carbonised to yield carbons with surface areas of at least $500 \mathrm{~m}^{2} \mathrm{~g}^{-1} \cdot{ }^{315-320}$ Other notable examples include $\mathrm{K}, \mathrm{Na}$, and Ca gluconate, ${ }^{315,321-323} \mathrm{Na}$ and $\mathrm{Ca}$ alginate, ${ }^{315}$ and potassium tartrate. $^{324} \mathrm{~K}$ salts of polymers such as poly(acrylamide-coacrylic acid), ${ }^{325} \mathrm{Na}$ salts of several forms of poly(styrene sulfonate), ${ }^{326-328}$ and even a $\mathrm{Zn}$ organic framework ${ }^{329}$ have been carbonised in order to build on structural voids in the precursor.

Use of organic salts as self-activation precursors means that porosity of the carbons is easily tuneable simply by changing the anion or cation. For example, Sevilla and Fuertes found that while pyrolysis at $800{ }^{\circ} \mathrm{C}$ of potassium gluconate or citrate yields relatively high surface area and highly microporous carbons, the equivalent Ca salts produce a greater degree of mesoporosity in the resultant carbon. ${ }^{315}$ Pyrolysis of $\mathrm{Mg}, \mathrm{Zn}$, and Fe salts also results in highly mesoporous carbons. ${ }^{318-320}$ Indeed, mesoporous carbons derived from magnesium citrate and zinc glycolate have pore volumes in excess of $2.5 \mathrm{~cm}^{3} \mathrm{~g}^{-1} \cdot 318,330$ The pore structure of carbons derived from Na salts often lie somewhere in the middle, typically having hierarchical (microporous plus meso- or macroporous) PSDs. ${ }^{321,326-328,331}$ The identity of the cation can also affect pore shape, for example carbonisation of sodium gluconate produces unusually long, narrow slit-shaped pores, whereas pores in calcium gluconate derived carbons have a more cellular structure. ${ }^{315,332}$ On the other hand, anion composition and structure seems to have a greater effect on large scale morphological features rather than the fine pore structure. ${ }^{133}$ For example, while salts of smaller anions like gluconate and citrate can be used to produce regular, sheet-like structures under appropriate conditions, polymeric salts typically yield carbons with a much lower degree of structural regularity. ${ }^{315,321,322,326,327,333,334}$

Despite the easily tuneable porosity of organic saltderived carbons, reports on their application as gas storage media are minimal. By far the dominant application of such materials appears to be as electrodes for supercapacitors, ${ }^{315,316,319,320,330,334,335}$ however their use as (electro)catalysts, ${ }^{319,322,329}$ as well as ion storage ${ }^{318,331}$ and battery ${ }^{326,336}$ materials is well documented. This may be due to the fact that although microporous carbons can easily be formed from organic salts, the surface areas of such materials are typically quite low $\left(<1500 \mathrm{~m}^{2} \mathrm{~g}^{-1}\right)$. Of course some gas storage/capture applications require more hierarchical micro-mesoporous pore structure, but surface areas of such carbons still seem to be largely limited to no more than $2000 \mathrm{~m}^{2} \mathrm{~g}^{-1}$. A notable exception to this are some carbons synthesised by Sevilla et al. from potassium citrate, which when carbonised with urea at 750$800{ }^{\circ} \mathrm{C}$ yields a carbon with surface area of up to $3350 \mathrm{~m}^{2} \mathrm{~g}^{-1}$ and pore volume $>2.0 \mathrm{~cm}^{3} \mathrm{~g}^{-1}$ which is relatively evenly divided between meso- and micropores. ${ }^{335}$ Such a material would be an interesting candidate for $\mathrm{CO}_{2}$ pressure swing adsorption (PSA) applications but unfortunately this wasn't examined by the authors. The sole instance of an organic salt-derived carbon being employed in gas storage/capture is that of potassium hydrogen phthalate (KHP). Uniquely narrow PSDs were achieved by researchers in the Mokaya group through gentle pyrolysis conditions producing carbons with a single micropore width. This is presumably the result of mechanistic differences when $\mathrm{K}^{+}$ (as opposed to the harsher $\mathrm{KOH}$ ) is the primary activating agent - that is, activation proceeds solely via intercalation of potassium ions into the pores. At temperatures above $800{ }^{\circ} \mathrm{C}$, the PSD 
begins to broaden resulting in higher surface area samples with $\mathrm{CO}_{2}$ capacities up to $4.5 \mathrm{mmol} \mathrm{g}^{-1}$ under ambient conditions. ${ }^{296,337}$

4.1.2. Precursor composition. It has been noted that the composition of the precursor, in particular the (atomic) $\mathrm{O} / \mathrm{C}$ ratio, may have a role to play in pore development upon both chemical and physical activation. Precursors with higher $\mathrm{O} / \mathrm{C}$ ratios are typically more susceptible to activation, and therefore may yield higher surface area carbons. ${ }^{77,135}$ These increases in surface area are however accompanied by PSD broadening and pore collapse, meaning that improvements in microporosity and thus low pressure storage/capture of small molecules may be facilitated by starting materials with lower $\mathrm{O} / \mathrm{C}$ ratios, known as activation-resistant precursors..$^{35,98}$ However, activation resistance may not be a direct function of precursor oxygen content; more complex factors such as the presence of specific oxygen containing moieties, the lignin content of ligno-cellulosic biomass, or the formation of highly stable composite structures during pyrolysis may confer activation resistance. ${ }^{80,98,251,338}$ For example, it has been shown the high stability of pure lignin, conferred by aromatic structures, means that is does not readily form pores on pyrolysis without the use of an activating agent, whereas dehydration reactions between hydroxyl groups during the pyrolysis of cellulose and hemi-cellulose confer three-dimensional porosity on the resultant carbon. ${ }^{338}$ Nonetheless it is possible to tailor pore sizes of carbons via careful selection of precursors according to their composition. For example, Pedicini et al. synthesised biochars from seaweed and wood chips and found that the $\mathrm{O} / \mathrm{C}$ ratio of the former was approximately $50 \%$ higher than that of the latter. When activated with $\mathrm{KOH}$, their surface areas were similar, however the carbons derived from wood chips had a much greater proportion of micropores. ${ }^{76}$ Similarly, Park et al. reported that when 'upgrading' commercial activated carbons by further activation with $\mathrm{KOH}$, the precursor with the higher $\mathrm{O} / \mathrm{C}$ ratio produced higher surface area, more mesoporous carbons whilst lower $\mathrm{O} / \mathrm{C}$ ratios lead to more microporous, low surface area carbons. They therefore concluded that precursors with higher $\mathrm{O} / \mathrm{C}$ ratios are more suited to synthesis of carbons for high pressure $\mathrm{CH}_{4}$ storage. $^{254}$ On the other hand Altwala and Mokaya investigated the textural properties and $\mathrm{CH}_{4}$ storage capacity of carbons synthesised from aircarbonised date seed, having a very low $\mathrm{O} / \mathrm{C}$ ratio of 0.21 . By increasing the $\mathrm{KOH}$ : precursor weight ratio to 2 to 4 , it was possible to retain much of the microporosity whilst doubling the surface area to over $2000 \mathrm{~m}^{2} \mathrm{~g}^{-1}$. The authors attributed the lack of so-called over-activation to the high activation resistance of carbonised date seeds. Porosity of carbons could be controlled via temperature or $\mathrm{KOH}$ : precursor ratio towards high gravimetric or volumetric methane capacity (25 ${ }^{\circ} \mathrm{C}$ and 35 bar) up to $11.4 \mathrm{mmol} \mathrm{g}^{-1}$ and $196 \mathrm{~cm}^{3}{ }_{\text {STP }} \mathrm{cm}^{-3}$, respectively. ${ }^{35}$

The $\mathrm{O} / \mathrm{C}$ ratio of a precursor can also be modulated according to pre-carbonisation conditions. For example, Zhen Zhang et al. synthesised a set of precursors by calcining glucosederived hydrochar in air at temperatures between 200 and
$300{ }^{\circ} \mathrm{C}$, as well as calcining pure glucose at $300{ }^{\circ} \mathrm{C}$, and also examined non-calcined hydrochar. These precursors differed most apparently due to the abundance of $\mathrm{COOH}$ moieties present on their surface (so-called ion exchange capacity) which varied from 0.22 to $3.92 \mathrm{mmol} \mathrm{g}^{-1}$. This corresponds to overall $\mathrm{O} / \mathrm{C}$ ratios in the range $0.37-0.45$. The authors posit that the presence of $\mathrm{COOH}$ is significant for activation via aqueous solution impregnation with $\mathrm{KOH}$, as the carboxyl group undergoes an ion-exchange reaction to form COOK. The closely bound $\mathrm{K}^{+}$can thus act as a more effective activating agent than if it were present in the form of $\mathrm{KOH}$. It was found that the content of ultramicropores was optimised for the activated carbon derived from hydrochar calcined at $300{ }^{\circ} \mathrm{C}$, having an ion exchange capacity of 3.92 (O/C ratio 0.45$)$. This sample showed the highest ambient $\left(25{ }^{\circ} \mathrm{C}, 1\right.$ bar $) \mathrm{CO}_{2}$ uptake of $4.3 \mathrm{mmol} \mathrm{g}^{-1}$. $^{251}$

This does not however mean that a pre-carbonisation or calcination step automatically improves a precursor's ability to form carbons with favourable porosity for small molecule adsorption. Balahmar et al. found that pre-treatment of precursors by hydrothermal carbonisation had either marginal or negative effects on the porosity of $\mathrm{KOH}$-activated carbons derived from a variety of biomasses. ${ }^{339}$ This may be a function of decreasing $\mathrm{O} / \mathrm{C}$ ratio and thus increasing resistance to activation.

A simple way to change precursor composition is simply to mix two precursors with significantly different compositions. An example of this is the mixing of polypyrrole (PPY) with sawdust hydrochar $(\mathrm{H})$ or raw sawdust $(\mathrm{SD})$ which have an $\mathrm{O} / \mathrm{C}$ ratio of $0.672,0.483$ and 0.773 , respectively (see Fig. 5). Researchers in the Mokaya group determined that a greater degree of control over porosity could be achieved by activating the mixed precursor than by activating any of the three alone. ${ }^{98,135,221,237}$ For samples activated with $\mathrm{KOH}$, porosity was mainly developed in the mesopore region. Increasing concentrations of $\mathrm{H}$ in a PPY-H mixture results in decreased mesoporosity, which is attributed to the decrease in $\mathrm{O} / \mathrm{C}$ ratio; more specifically the mesoporosity is a function of the amount of PPY in the mixture whereas the mesopore size is increased with increasing PPY: $\mathrm{H}$ ratio. ${ }^{98}$ However, the same does not apply to carbons synthesised by from mixtures of PPY and SD, wherein increased $\mathrm{O} / \mathrm{C}$ ratio actually results in higher a higher degree of microporosity and lower porosity over all. This is attributed to stabilising interactions between aromatic moieties on PPY and SD which confer resistance to activation. ${ }^{98}$ On the other hand, using a gentler activating agent (potassium oxalate) results in more hierarchical meso-microporous carbons, with optimised pore structure for high pressure $\mathrm{CO}_{2}$ capture. ${ }^{135}$ The appropriate selection of $\mathrm{Ppy}: \mathrm{H}$ ratio, activating agent and activation conditions can be used to produce carbons with a variety of porosities and textural characteristics suited to applications ranging from low pressure $\mathrm{CO}_{2}$ capture to high pressure $\mathrm{H}_{2}$ storage. ${ }^{98,135}$

4.1.3. Compactivation. Compactivation, also known as mechanochemical activation is a process first reported in 2015 by the Mokaya group, wherein a solid-solid mixture of precursor and activating agent is compressed into a pellet prior 

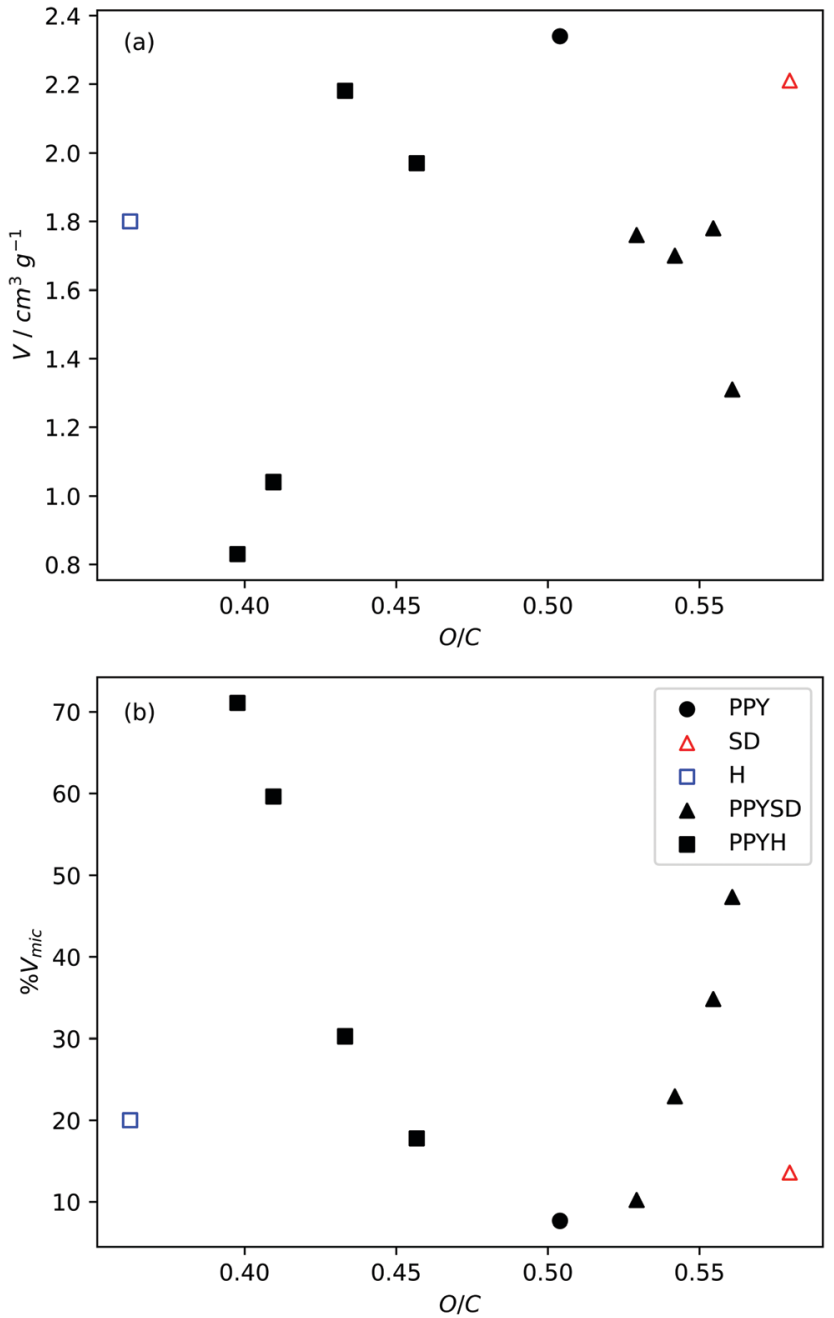

Fig. 5 Variation of pore volume and micropore percentage (by volume) with precursor $\mathrm{O} / \mathrm{C}$ ratio as controlled by mixing in different quantities the precursors polypyrrole (PPY), sawdust (SD) and sawdust hydrochar (H). Adapted from work by Balahmar et al. O/C ratio. All samples activated at $800{ }^{\circ} \mathrm{C}$ for $1 \mathrm{~h} .{ }^{98} \mathrm{O} / \mathrm{C}$ ratio determined using weighted sums of the O/C contents of PPY, $\mathrm{H}$, and SD.

to activation. The rationale of this step is to increase atomic proximity between the precursor and activating agents, in order to increase activating agent efficiency thus producing higher surface area carbons without broadening the PSD. In addition, carbons with relatively high surface areas and pore volumes can be produced at unusually low activation temperatures. ${ }^{238,248}$ Table 4 compares the porosity and gas uptake capacity of materials derived through conventional activation and compactivation. Although a variety of precursors have been tested for compactivation, thus far materials have only been reported where $\mathrm{KOH}$ is used as an activating agent. Compactivated samples thus show superior $\mathrm{CO}_{2}$ and $\mathrm{H}_{2}$ capacity over similar conventionally activated carbons at pressures up to 50 bar. $^{237,238,248}$ Interestingly due to the high packing density of compactivated carbons, improvements in $\mathrm{CO}_{2}$ uptake are more obvious from a volumetric perspective. For example, a compactivated carbon derived from polypyrrole using $\mathrm{KOH}$ at a ratio of 4 and activation temperature of $800{ }^{\circ} \mathrm{C}$ achieved a $\mathrm{CO}_{2}$ uptake of $48 \mathrm{~g} \mathrm{~L}^{-1}$ at 1 bar and $25^{\circ} \mathrm{C}$; an improvement of $37 \%$ over its conventionally activated counterpart. This increase is more than triple that of the improvement in gravimetric uptake. ${ }^{237}$ The porosity of compactivated carbons remains highly tuneable, with carbons being produced for either high or low pressure $\mathrm{CO}_{2}$ capture by simply modulating activation temperature. $^{81}$

In 2018 Rambau et al. reported mesoporous compactivated carbons from used tyre-derived char, however surface areas of the reported carbons do not approach those in other studies under similar conditions. ${ }^{340}$ This may be a result of the char's relatively high carbon content and associated resistance to activation. An alternative explanation is that the compaction pressure was limited to $10 \mathrm{MPa}$ whereas other studies used up to $740 \mathrm{MPa}$. Despite the clear advantages of compactivation for carbons for gas storage/capture applications there has been very little published on the topic in the past few years. As such, there is as yet no information on the effect of compaction pressure and duration on the porosity of synthesised carbons.

\subsection{Zeolite templated carbons}

While the synthesis of ZTCs continues to be a popular area of research, ${ }^{34,172,193,341-344}$ articles reporting their application in the adsorption of $\mathrm{CO}_{2}, \mathrm{H}_{2}$ or $\mathrm{CH}_{4}$ have dwindled in the past

Table 4 Comparison of porosity and gas uptake of carbons derived through conventional activation or compactivation. Values in italics are for compactivated samples

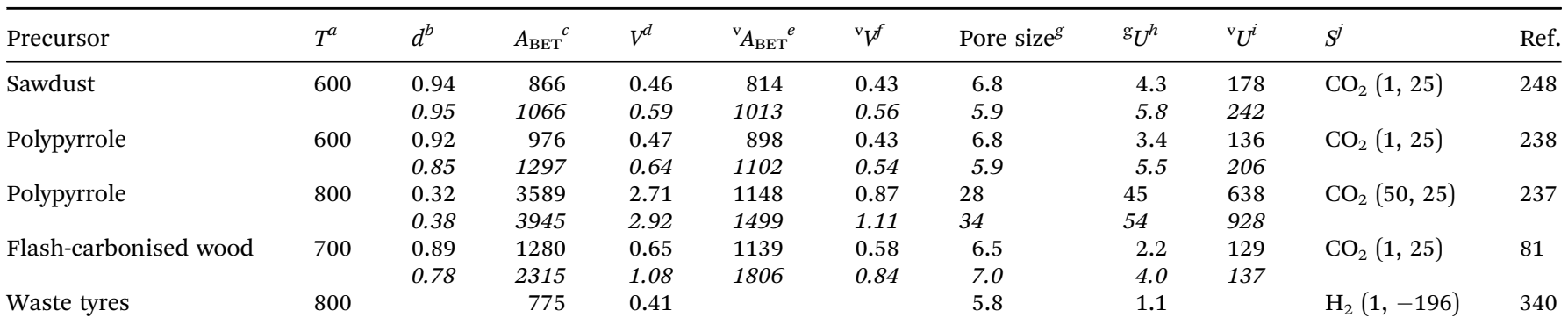

${ }^{a}$ Activation temperature $\left({ }^{\circ} \mathrm{C}\right) .{ }^{b}$ Packing density $\left(\mathrm{g} \mathrm{cm}{ }^{-3}\right) .{ }^{c}$ BET surface area $\left(\mathrm{m}^{2} \mathrm{~g}^{-1}\right) .{ }^{d}$ Total pore volume $\left(\mathrm{cm}^{3} \mathrm{~g}^{-1}\right) .{ }^{e}$ Volumetric BET surface area $\left(\mathrm{m}^{2} \mathrm{~cm}^{-3}\right) .{ }^{f}$ Volumetric pore volume $\left(\mathrm{cm}^{3} \mathrm{~cm}^{-3}\right) .{ }^{g}$ Pore size taken from centre of most prominent peak in PSD. ${ }^{h}$ Gravimetric uptake, in mmol $\mathrm{g}^{-1}$ for $\mathrm{CO}_{2}$ and wt\% for $\mathrm{H}_{2} \cdot{ }^{i}$ Volumetric uptake $\left(\mathrm{g} \mathrm{dm}{ }^{-3}\right) .{ }^{j}$ Adsorbate gas $\left(\mathrm{CO}_{2}\right.$ or $\left.\mathrm{H}_{2}\right)$; values in parenthesis are pressure (bar) and temperature $\left({ }^{\circ} \mathrm{C}\right)$. 
three years. In fact since 2018 there exist only nine journal articles on the subject of capture/storage of these molecules in ZTCs. ${ }^{194,256,257,345-350}$ Furthermore, of these papers two are based on simulations of hypothetical optimized ZTCs. ${ }^{257,345}$ While these provide insights into what an optimal ZTC structure might be for these applications, they do not provide novel methods for modulating ZTC porosity. ${ }^{257,345}$ This may be due to a consensus within the community that the more facile synthesis of ACs leads to materials whose pore geometry is more suitable for small molecule sorption. Nonetheless the templating approach provides interesting and unique opportunities for modulation of porosity for use in storage of $\mathrm{H}_{2}$ as well as $\mathrm{CO}_{2}$ capture. In the case of $\mathrm{CH}_{4}$ however, ZTCs have severe limitations on their volumetric storage capacity meaning that they are less feasible as ANG sorbents, ${ }^{34,240,351}$ although there has been a recent noteworthy attempt to improve volumetric porosity of ZTCs to this end. ${ }^{194}$

4.2.1. Choice of reagents. It has long been established that replication of the zeolite template and thus maximisation of ZTC porosity requires that the carbon source can easily diffuse into pore channels. As such the choice of potential carbon sources is narrowed to small, volatile, unsaturated organics in the case of carbon introduction via CVD ${ }^{64,179,189-192,195,197,198}$ while for LI, furfuryl alcohol is the reagent of choice. ${ }^{88,174,178-182}$ For example, in 2010 Xia $e t$ al. reported on the effects of the use of various carbon sources on textural outcomes and template replications using a combination of both CVD and LI techniques. Structural replication and porosity were maximised by templating of zeolite-Y using ethylene in a two-step CVD synthesis. Consequently this carbon with $A_{\mathrm{BET}}$ of $2164 \mathrm{~m}^{2} \mathrm{~g}^{-1}$, >90\% microporosity and a narrow PSD achieved the highest cryogenic $\left(-196{ }^{\circ} \mathrm{C}\right) \mathrm{H}_{2}$ storage capacity in the sample set of 4.9 and $1.9 \mathrm{wt} \%$ at 20 and 1 bar, respectively. Carbons derived via a combination of LI and CVD could approach similar levels of overall porosity and $\mathrm{H}_{2}$ capacity as the aforementioned sample, but at the cost of PSD broadening and less faithful replication of the zeolitic structure. ${ }^{190}$ Table 5 illustrates the effects of the use of different templates, carbon sources, and carbon introduction methods on ZTC porosity.

In recent years attempts have been made to use alternative carbon sources such as sucrose. In order to be used for LI the disaccharide must be dissolved. Wijiyanti et al. produced a ZTC with moderate surface area $\left(932 \mathrm{~m}^{2} \mathrm{~g}^{-1}\right)$ and pore volume $\left(0.97 \mathrm{~cm}^{3} \mathrm{~g}^{-1}\right)$ with hierarchical porosity using sucrose dissolved in $\mathrm{H}_{2} \mathrm{SO}_{4}$, resulting in a material which allows rapid ingress of $\mathrm{H}_{2}$ (at $30-50{ }^{\circ} \mathrm{C}$ and 1 bar) into the porous structure. ${ }^{346}$ While the bulk of the literature has focused on using pristine carbon sources in synthesis of ZTCs, Musyoka et al. found that a 'dirty' source, namely the pyrolysis gases from used tyres can be used as a CVD vapour (see Table 5). The vapour is composed primarily of small aromatic molecules. When performed following LI templation with furfuryl alcohol on zeolite-13X, the resulting carbons exhibited higher porosity (3254 $\mathrm{m}^{2} \mathrm{~g}^{-1}$ and $91 \%$ microporosity) compared to those derived using ethylene in the second (CVD) step. Indeed, carbons produced using tyre pyrolysis vapour as a CVD source exhibit a narrower PSD than those conventionally-produced ZTCs. High $\mathrm{H}_{2}$ storage capacity of $2.5 \mathrm{wt} \%$ was achieved at $-196{ }^{\circ} \mathrm{C}$ and 1 bar. ${ }^{348}$ Although $\mathrm{H}_{2}$ adsorption was not measured above atmospheric pressure, both the ZTC textural characteristics and the trajectory of the reported isotherm indicate this carbon may be suited to higher pressure applications.

The introduction of nitrogen into the structure of ZTCs is meant to improve adsorption of small molecules due to improved adsorbate-adsorbent interactions - typically this is performed by using a nitrogen-rich carbon source. ${ }^{179,253,353,354}$ Such methods also tend to have the side-effect of changing the porosity of the ZTC. For example, Dewi and Widiastuti found

Table 5 Summaries of synthetic procedures, porosity and $\mathrm{H}_{2}$ uptake capacity for selected ZTCs

\begin{tabular}{|c|c|c|c|c|c|c|c|}
\hline \multirow[b]{2}{*}{ Template } & \multicolumn{2}{|l|}{ Carbonisation $^{a}$} & \multirow[b]{2}{*}{$A_{\mathrm{BET}}^{b}$} & \multirow[b]{2}{*}{$V^{c}$} & \multirow{2}{*}{$\begin{array}{l}\mathrm{H}_{2} \text { uptake } \\
\text { conditions }{ }^{d}\end{array}$} & \multirow{2}{*}{$\begin{array}{l}\mathrm{H}_{2} \text { uptake }^{e} \\
\mathrm{wt} \%\end{array}$} & \multirow[b]{2}{*}{ Ref. } \\
\hline & Step 1 & Step 2 & & & & & \\
\hline $\mathrm{NaY}$ & FA (LI, 700) & PP (CVD, 900) & 3590 & & $f_{-196,24}$ & 5.5 & 245 \\
\hline Y & ET (CVD, 900) & & 2000 & $1.11(0.83)$ & $-196,1$ & 1.8 & 190 \\
\hline $\mathrm{Y}$ & ET (CVD, 900) & ET $(C V D, 900)$ & 2160 & $1.26(0.92)$ & $-196,1$ & 1.9 & 190 \\
\hline Y & FA $(\mathrm{LI}, 900)$ & & 860 & $0.93(0.24)$ & $-196,1$ & 0.7 & 190 \\
\hline Y & FA (LI, 900) & ET (CVD, 900) & 1940 & $1.18(0.73)$ & $-196,1$ & 1.6 & 190 \\
\hline Y & Sucrose/AN (LI, 800) & & 1670 & $2.28(0.55)$ & 31,1 & 3.9 & 352 \\
\hline $13 \mathrm{X}$ & FA (LI, 700) & $\begin{array}{l}\text { Tyre pyrolysis vapour } \\
\text { (CVD, 900) }\end{array}$ & 3250 & $1.72(1.61)$ & $-196,1$ & 2.5 & 348 \\
\hline $13 \mathrm{X}$ & FA $(\mathrm{LI}, 700)$ & ET $(C V D, 900)$ & 3340 & $1.88(1.72)$ & $-196,1$ & 1.9 & 348 \\
\hline Clinoptilolite & $1: 5$ glucose/urea (LI, 900) & & 66 & $0.32(0.00)$ & & & 350 \\
\hline Clinoptilolite & 2:5 glucose/urea (LI, 900) & & 151 & $0.36(0.03)$ & & & 350 \\
\hline $\mathrm{Y}$ & $\mathrm{ET}(\mathrm{CVD}, 790)$ & & 1930 & $0.97^{f}(0.73)$ & & & 193 \\
\hline
\end{tabular}

${ }^{a}$ Carbon source, followed by carbonisation method and, in parenthesis the carbonisation technique (LI or CVD) and temperature $\left({ }^{\circ} \mathrm{C}\right)$; FA $=$ furfuryl alcohol, ET = ethylene, $\mathrm{PP}=$ polypropylene, $\mathrm{AN}=$ acetonitrile. ${ }^{b}$ BET surface area $\left(\mathrm{m}^{2} \mathrm{~g}^{-1}\right) .{ }^{c}$ Pore volume $\left(\mathrm{cm}^{3} \mathrm{~g}^{-1}\right)$; values in parenthesis are micropore volume. ${ }^{d}$ Temperature $\left({ }^{\circ} \mathrm{C}\right.$ ) and pressure (bar) at which $\mathrm{H}_{2}$ uptake was measured. ${ }^{e} \mathrm{H}_{2}$ uptake capacity (wt\%). ${ }^{f}$ No total pore volume reported, thus sum of $V_{\text {micro }}$ and $V_{\text {meso }}$ is used. 
that mixing small amounts of acetonitrile into a sucrose solution prior to its use as an LI carbon source on zeolite-Y resulted in a ZTC with increased surface area (1250 to $\left.1670 \mathrm{~m}^{2} \mathrm{~g}^{-1}\right)$ and increased microporosity from 5 to $24 \%$. However, with increasing concentrations of the nitrogen dopant, overall surface area falls to $867 \mathrm{~m}^{2} \mathrm{~g}^{-1}$ along with absolute microporosity. ${ }^{352}$ Similarly, Rangel-Sequeda et al. have recently shown that increasing the amount of urea in a urea-glucose mixture resulted in higher surface area carbons when the mixture was used as an LI agent on the natural zeolite (clinoptilolite) template. ${ }^{350}$ While the former did measure $\mathrm{H}_{2}$ storage capacity and the latter $\mathrm{CO}_{2}$ capture, it is impossible to disentangle the effects of improved porosity and chemical doping on the improved uptakes.

Template modification. A major stumbling block with the use of microporous zeolites as hard templates for carbons is that if the structure is replicated well, the PSD will invariably be unimodal. This lack of pore hierarchy can limit the gas storage/capture capacity of such ZTCs due to slow ingress into pores. Similarly, problems can arise in the synthesis of ZTCs if the carbon source cannot easily enter the narrow channels. ${ }^{355,356}$ Mesopores can be created in zeolites (while retaining microporosity) by the use of surfactant-templating wherein the material is steamed in order to partially remove aluminium from the framework $^{357}$ thus yielding hierarchical templates. Aumond et al. achieved ZTCs with approximately equal micropore and mesopore volume by CVD using ethylene on a surfactanttemplated zeolite-Y. The product showed an increase in total pore volume from 0.97 to $1.59 \mathrm{~cm}^{3} \mathrm{~g}^{-1}$ relative to a ZTC derived by templating on non-treated zeolite. ${ }^{193}$ Although not measured, such a material is an interesting candidate for $\mathrm{CO}_{2}$ pressure swing adsorption applications.

4.2.2. Post-synthetic treatment. In some cases, the porosity of ZTCs can be modified after synthesis. This can be achieved by forming composites with some other material, however by definition the composite's porosity is then a result of the structures of both the ZTC and the other material. ${ }^{358,359}$ On the other hand, Choi et al. found that through thermal treatment of ZTCs, a contraction in the width of micropores is produced, associated with loss of structural hydrogen, improved packing density and decreased gravimetric porosity. Consequently, volumetric methane capacity ( 65 bar, $25^{\circ} \mathrm{C}$ ) was improved by $7 \%$ from 164 to $176 \mathrm{~cm}_{\text {STP }}^{3} \mathrm{~cm}^{-3}$ on a ZTC synthesised using BEA as a template, following heat treatment at $600{ }^{\circ} \mathrm{C} .{ }^{194}$ Other thermal, chemical and pressure treatments can lead to greater improvements in porosity and therefore improved gas uptakes.

Densification. Densification, also known as compaction or pelletisation is a process used to improve the volumetric storage of small molecules on carbons by compressing the skeletal structure i.e. increasing the packing density. As early as 2005, Celzard and Fierro found that increasing the apparent density of AC powders resulted in an approximately proportional improvement in volumetric methane capacity at 35 bar and $20{ }^{\circ} \mathrm{C}$. Increases in apparent density did however lead to reductions in gravimetric uptake, thus densification pressure should be optimised. ${ }^{360}$ Early attempts to increase density of ZTCs utilised so-called hot densification wherein pressures up to $147 \mathrm{MPa}$ and temperatures up to $300{ }^{\circ} \mathrm{C}$ were used in order to convert the diffuse ZTC powder into a dense, compact pellet. ${ }^{258,361}$ While studying the hot densification $\left(300{ }^{\circ} \mathrm{C}\right)$ of a ZTC derived from zeolite-Y (Na-form), Hou et al. found that although gravimetric surface area decreased with increasing compaction pressure, the opposite trend was found when surface area is measured volumetrically. ${ }^{361}$ Similarly Guan et al. found that hot densification of a ZTC halved gravimetric measures of porosity, while doubling their volumetric counterparts. As a result, volumetric $\mathrm{CH}_{4}$ storage capacity (at 35 bar and $25{ }^{\circ} \mathrm{C}$ ) was improved from 60 to $127 \mathrm{~cm}^{3}{ }_{\text {STP }} \mathrm{cm}^{-3}$ for the pristine and compacted ZTC, respectively. ${ }^{258}$ Gravimetric porosity generally decreases following densification, but to varying degrees depending on the compaction conditions and nature of the ZTC. ${ }^{178,182,362}$ However, a report from Almasoudi et al. indicates that if compaction pressure is sufficiently low (370 MPa), gravimetric surface area can increase alongside volumetric porosity resulting in improved gravimetric and volumetric $\mathrm{H}_{2}$ capacity. ${ }^{363}$ As for pore size, compaction generally leads to the development of further microporosity and/or shifting of the PSD and average pore size towards the ultramicropores region as pores contract under pressure, ${ }^{178,361,363}$ which may result in improved low pressure gas uptake. Fig. 6 illustrates the effect of densification pressure on various measures of porosity.

More recently, work by Balahmar et al. compared the result of compacting a ZTC to the compaction of the zeolite scaffold prior to templation (so-called pre-compaction) on the textural characteristics and $\mathrm{H}_{2}$ and $\mathrm{CO}_{2}$ storage capacities of the resultant ZTCs. Materials were synthesised on zeolite-13X or $-\mathrm{Y}$ templates using CVD of acetonitrile. It was found that precompaction actually increased gravimetric porosity in terms of both surface area and pore volume as compared with the conventional ZTC. Furthermore, packing density increased by over $50 \%$ from 0.53 to $0.82 \mathrm{~g} \mathrm{~cm}^{-3}$. This resulted in simultaneous improvement to gravimetric (11.6 to $13.1 \mathrm{mmol} \mathrm{g}^{-1}$ ) and volumetric (271 to $473 \mathrm{v} / \mathrm{v}$ ) $\mathrm{CO}_{2}$ uptake at moderate pressure (20 bar and $25{ }^{\circ} \mathrm{C}$ ). Conversely, post-compaction had almost no effect on gravimetric storage and showed only mild improvements volumetrically. ${ }^{182}$ A recent paper by Gabe et al. detailed the optimisation of densification conditions for a ZTC mixed with reduced graphene oxide. The authors found that volumetric $\mathrm{H}_{2}$ storage was doubled at all pressures from 0 to $100 \mathrm{bar}$, when the zeolite-Y-derived carbon was subjected to compaction at $150{ }^{\circ} \mathrm{C}$ and $145 \mathrm{MPa}$. The densified composite also has the advantage of being extremely mechanically robust. ${ }^{364}$

Activation. The porosity of templated carbons can be expanded via chemical or physical activation; for example the porosity of mesoporous carbons formed when using a silica template can be expanded into the micropore region on activation with $\mathrm{KOH}$ or $\mathrm{CO}_{2} \cdot{ }^{61,365,366}$ With the advent of microporous templated carbons based on zeolites, researchers have attempted activation to both improve absolute, overall 

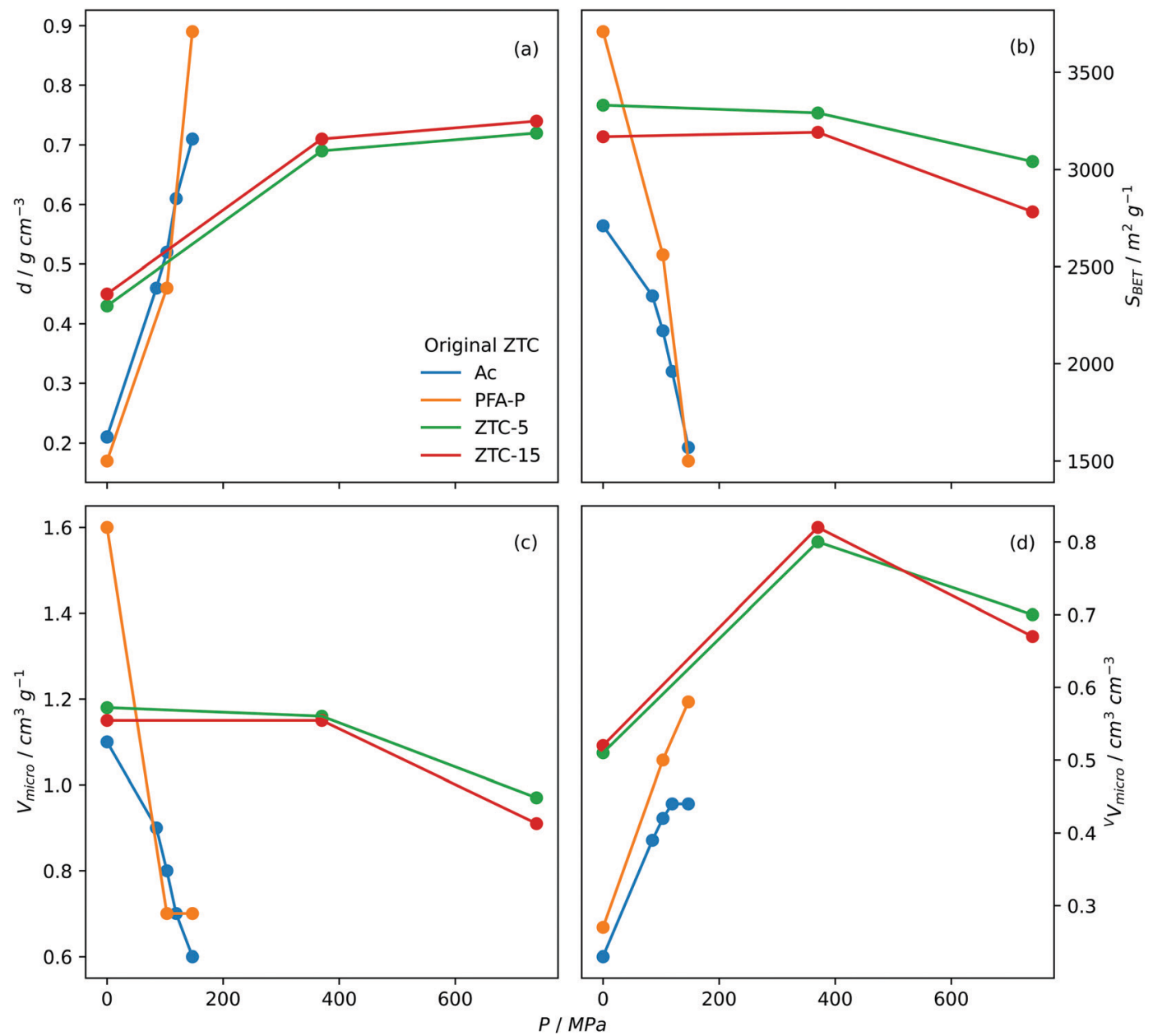

Fig. 6 Trends in (a) packing density, (b) BET surface area, (c) gravimetric micropore volume and (d) volumetric micropore volume of densified ZTCs with densification pressure. Ac and PFA-P both templated on Na-zeolite $Y$ with Ac synthesized via acetylene CVD and PFA-P via polyfurfuryl alcohol LI followed by propylene CVD. Densification performed at $300{ }^{\circ} \mathrm{C} .{ }^{361} \mathrm{ZTC}-5$ and ZTC-15 synthesized via polyfurfuryl alcohol LI followed by ethylene CVD on zeolite 13X. 5 and 15 refer to the ramp rate used in the first carbonisation step. ${ }^{178}$

microporosity and extend porosity into the mesopore region. The activating agent of choice has become $\mathrm{KOH}$ as unlike $\mathrm{CO}_{2}$ it can improve overall porosity without destroying the intricate network of micropores already present in the ZTC..$^{83,88,367}$ Inevitably, activation of ZTCs leads to destruction of much of the crystal structure meaning that the narrow PSDs which ZTCs are prized for are not present in activated-ZTCs, ${ }^{34}$ although work by Anggarini et al. suggests that increased ordering can be achieved via activation with $\mathrm{ZnCl}_{2} \cdot{ }^{368}$ Relatively aggressive $\mathrm{KOH}$-activation $\left(700-800{ }^{\circ} \mathrm{C}, 4: 1 \mathrm{w} / \mathrm{w}\right)$ leads to doubling or even tripling of overall surface area according to work done in the Mokaya group. At the same time much, but not all of the original microporosity is retained. ${ }^{83,88,199}$ However, it is not yet clear to what extent the initial porosity of the ZTC influences that of the activated ZTC. For example, $\mathrm{KOH}$ activated carbons with surface areas around $3000 \mathrm{~m}^{2} \mathrm{~g}^{-1}$ can be produced from ZTCs with initial surface area as low as $367 \mathrm{~m}^{2} \mathrm{~g}^{-1}$ and as high as $1670 \mathrm{~m}^{2} \mathrm{~g}^{-1} \cdot{ }^{83,367}$ In fact, in one case ZTCs with the highest initial porosity show the smallest improvements following activation. ${ }^{88}$ This unclear relationship is probably a result of entangled variables such as ZTC structural type and elemental composition. ${ }^{34,77,135}$ The benefit of activation of ZTCs is somewhat questionable as the highest surface area achieved through this technique is only around $3350 \mathrm{~m}^{2} \mathrm{~g}^{-1}$, significantly less than the record for conventionally activated carbons ${ }^{82}$ or indeed non-activated ZTCs. ${ }^{369}$

Nevertheless, activation of ZTCs can lead to nearly doubling of cryogenic hydrogen storage capacity at $20 \mathrm{bar}^{83,88}$ On the other hand improvements are not nearly as significant for applications wherein pore size, rather than overall surface area or porosity is the more significant factor in determining gas uptake. For example, Almasoudi et al. showed that despite improvements in overall surface area upon $\mathrm{KOH}$-activation of a carbon derived from the templation of furfuryl alcohol on a zeolitic imidazole framework, ambient gravimetric $\mathrm{CO}_{2}$ capacity could not be improved by more than $23 \%$. Even more striking are accompanying decreases (up to $78 \%$ ) in $\mathrm{CO}_{2}$ uptake density. This is attributed to significant destruction of micropores during the activation process. ${ }^{199}$ More recently Susanti and Widiastuti reported KOH-activation of a zeolite-Y 
templated carbon (ZTC-Y) synthesised via LI. They report that improvement in $\mathrm{CO}_{2}$ (ambient pressure, $30{ }^{\circ} \mathrm{C}$ ) capture capacity is optimised at a $\mathrm{KOH}$ : ZTC-Y ratio of 1.5 from $0.24 \mathrm{mmol} \mathrm{g}^{-1}$ to $0.62 \mathrm{mmol} \mathrm{g}^{-1}$. Interestingly, activation of ZTC-Y is accompanied by a reduction in total surface area and simultaneous decrease in average pore width. This lends further credence to the vital role of pore size in such applications. ${ }^{256}$

\section{Summary and outlook}

Experimental control over the porosity of ZTCs and ACs is now well established, with a variety of routes to high surface area carbons possessing either unimodal or hierarchical porosities. As a result, it is possible to achieve carbons with consistently appropriate porosity for good gravimetric uptake of gases under a variety of conditions. For example, there are multiple routes to the narrow PSDs with high surface area useful in $\mathrm{H}_{2}$ storage. For cyclic $\mathrm{CO}_{2}$ capture applications, hierarchical carbons with moderate porosity can be formed both via the templation or activation routes. Paradoxically, of the three sorptives examined in this review, $\mathrm{CH}_{4}$ while the most commercially developed has seen the lowest degree of development in so far as determination of optimal porosity for sorption on carbons. As such, works on porosity modulation for this particular application are limited.

Materials with high volumetric capacity are significantly under-investigated, a metric which is particularly relevant to $\mathrm{CH}_{4}$ storage. While there have been some significant and interesting methods used to improve packing density and volumetric porosity of carbons via post-synthetic methods or by altering experimental conditions, work in this area is fairly limited and seems to be restricted to a handful of research groups. In particular, techniques such as compaction and densification have showed a lot of promise but the full effects of the balance of variables such as compaction time, pressure and temperature are yet to be examined - in stark contrast to well-established techniques like $\mathrm{KOH}$-activation.

ACs show more promise than ZTCs as, despite their amorphous structure, it is at least as facile to control their porosity for any given application. Furthermore, conditions and reagents for AC synthesis typically require less precision than those needed for ZTCs resulting in reduced costs and the ability to use abundant and low value recycled materials. Besides for many applications, the exquisitely uniform porosity found in ZTCs is not necessary, and indeed the dearth of literature surrounding $\mathrm{CH}_{4}$ adsorption on ZTCs reflects this. Their greatest utility appears to be in hydrogen storage where extremely homogenous pore widths are required. Further work is needed to determine whether good ZTC carbon sources can be generated from waste materials, and to determine the simplest routes to good ZTC porosity.

\section{Author contributions}

L. Scott Blankenship: Investigation, Visualisation, Writing original draft. Robert Mokaya: Conceptualization, Funding acquisition, Supervision, Writing - review \& editing.

\section{Conflicts of interest}

There are no conflicts to declare.

\section{Acknowledgements}

We are thankful to the EPSRC (Low-Dimensional Materials \& Interfaces DTP) for a studentship for LSB. RM thanks the Royal Society for a Royal Society Wolfson Research Merit Award.

\section{Notes and references}

1 V. Ramanathan and Y. Xu, Proc. Natl. Acad. Sci. U. S. A., 2010, 107, 8055-8062.

2 V. Masson-Delmotte, P. Zhai, H.-O. Pörtner, D. C. Roberts, J. Skea, P. R. Shukla, A. Pirani, W. Moufouma-Okia, C. Péan and R. Pidcock, Global warming of $1.5{ }^{\circ}$ C: Summary for policy makers, 2018.

3 C.-F. Schleussner, J. Rogelj, M. Schaeffer, T. Lissner, R. Licker, E. M. Fischer, R. Knutti, A. Levermann, K. Frieler and W. Hare, Nat. Clim. Change, 2016, 6, 827-835.

4 T. Kuramochi, A. Ramírez, W. Turkenburg and A. Faaij, Prog. Energy Combust. Sci., 2012, 38, 87-112.

5 C.-C. Lin, R.-X. He and W.-Y. Liu, Energies, 2018, 11, 3432.

6 G. P. Peters, R. M. Andrew, J. G. Canadell, S. Fuss, R. B. Jackson, J. I. Korsbakken, C. Le Quéré and N. Nakicenovic, Nat. Clim. Change, 2017, 7, 118-122.

7 R. Clémençon, J. Environ. Dev., 2016, 25, 3-24.

8 UK becomes first major economy to pass net zero emissions law, https:/www.gov.uk/government/news/ukbecomes-first-major-economy-to-pass-net-zero-emissionslaw, accessed 23rd of March, 2021.

9 S. Choi, J. H. Drese and C. W. Jones, ChemSusChem, 2009, 2, 796-854.

10 U. Eberle, B. Müller and R. Von Helmolt, Energy Environ. Sci., 2012, 5, 8780-8798.

11 M. S. Dresselhaus and I. L. Thomas, Nature, 2001, 414, 332-337.

12 K. V. Kumar, K. Preuss, M.-M. Titirici and F. RodríguezReinoso, Chem. Rev., 2017, 117, 1796-1825.

13 I. Angelidaki, L. Treu, P. Tsapekos, G. Luo, S. Campanaro, H. Wenzel and P. G. Kougias, Biotechnol. Adv., 2018, 36, 452-466.

14 T. A. Makal, J.-R. Li, W. Lu and H.-C. Zhou, Chem. Soc. Rev., 2012, 41, 7761-7779.

15 D. M. D'Alessandro, B. Smit and J. R. Long, Angew. Chem., Int. Ed., 2010, 49, 6058-6082.

16 Q. Wang, J. Luo, Z. Zhong and A. Borgna, Energy Environ. Sci., 2011, 4, 42-55.

17 M. Cozier, Greenhouse Gases: Sci. Technol., 2019, 9, 1084-1086.

18 D. Lozano-Castello, J. Alcaniz-Monge, M. De la Casa-Lillo, D. Cazorla-Amoros and A. Linares-Solano, Fuel, 2002, 81, 1777-1803. 
19 J. Romanos, S. Sweany, T. Rash, L. Firlej, B. Kuchta, J. Idrobo and P. Pfeifer, Adsorpt. Sci. Technol., 2014, 32, 681-691.

20 M. Sevilla and R. Mokaya, Energy Environ. Sci., 2014, 7, 1250-1280.

21 L. Schlapbach and A. Züttel, Mater. Sustainable Energy, 2011, 265-270.

22 R. E. Morris and P. S. Wheatley, Angew. Chem., Int. Ed., 2008, 47, 4966-4981.

23 Z. Liang, K. Fu, R. Idem and P. Tontiwachwuthikul, Chin. J. Chem. Eng., 2016, 24, 278-288.

24 K. S. Fisher, K. Searcy, G. T. Rochelle, S. Ziaii and C. Schubert, Advanced Amine Solvent Formulations and Process Integration for Near-term CO2 Capture Success, Trimeric Corporation, 2007.

25 P. Pfeifer, L. Aston, M. Banks, S. Barker, J. Burress, S. Carter, J. Coleman, S. Crockett, C. Faulhaber and J. Flavin, Chaos, 2007, 17, 41108.

26 Y. He, W. Zhou, G. Qian and B. Chen, Chem. Soc. Rev., 2014, 43, 5657-5678.

27 D. Farrusseng, Metal-organic Frameworks: Applications from Catalysis to Gas Storage, John Wiley \& Sons, 2011.

28 M. Ding, R. W. Flaig, H.-L. Jiang and O. M. Yaghi, Chem. Soc. Rev., 2019, 48, 2783-2828.

29 J.-Y. Lee, C. D. Wood, D. Bradshaw, M. J. Rosseinsky and A. I. Cooper, Chem. Commun., 2006, 2670-2672.

30 M. Pera-Titus, Chem. Rev., 2014, 114, 1413-1492.

31 R. V. Siriwardane, M.-S. Shen, E. P. Fisher and J. Losch, Energy Fuels, 2005, 19, 1153-1159.

32 J. Weitkamp, M. Fritz and S. Ernst, Zeolites as media for hydrogen storage, Elsevier, Montreal, 1992.

33 R. Krishna and J. M. van Baten, J. Membr. Sci., 2010, 360, 323-333.

34 H. Nishihara and T. Kyotani, Chem. Commun., 2018, 54, 5648-5673.

35 A. Altwala and R. Mokaya, Energy Environ. Sci., 2020, 13, 2967-2978.

36 C. $\mathrm{Xu}$ and M. Stromme, Nanomaterials, 2019, 9, 103.

37 I. Toda, H. Toda, H. Akasaka, S. Ohshio, S. Himeno and H. Saitoh, J. Ceram. Soc. Jpn., 2013, 121, 464-466.

38 S. Alhasan, R. Carriveau and D.-K. Ting, Int. J. Environ. Studies, 2016, 73, 343-356.

39 iNatGas, The Natural Gas Industry Solutions, https://inat gas.com/, accessed 12th December, 2021.

40 Natural Gas Fueling Infrastructure Development, https:// afdc.energy.gov/fuels/natural_gas_infrastructure.html, accessed 21st December, 2021.

41 G. Basich and T. Dao, CNG Use Expands Among Government Agencies, https://www.government-fleet.com/152834/ cng-use-expands-among-government-agencies, accessed 21st December, 2021.

42 Shell, Liquefied Natural Gas (LNG), https://www.shell.com/ energy-and-innovation/natural-gas/liquefied-natural-gaslng.html, accessed 21st December, 2021.

43 Ingevity, Adsorbed Natural Gas, https://www.ingevity.com/ markets/adsorbed-natural-gas/, accessed 21st December, 2021.
44 Daigas, Biogas purification and adsorption storage system, https://www.daigasgps.co.jp/en/service/engineering/energy/ biogas_stocksystem/, accessed 21st December, 2021.

45 M. Smith and J. Gonzales, Costs associated with compressed natural gas vehicle fueling infrastructure, National Renewable Energy Lab. (NREL), Golden, CO (United States), 2014.

46 A. Y. Tsivadze, O. E. Aksyutin, A. G. Ishkov, I. E. Men'shchikov, A. A. Fomkin, A. V. Shkolin, E. V. Khozina and V. A. Grachev, Russ. Chem. Rev., 2018, 87, 950-983.

47 P. Greene, Basics of Biogas Upgrading, https://www.bio cycle.net/basics-biogas-upgrading/, accessed 21st December, 2021.

48 F. Bauer, T. Persson, C. Hulteberg and D. Tamm, Biofuels, Bioprod. Biorefin., 2013, 7, 499-511.

49 T. Kvist and N. Aryal, Waste Manage., 2019, 87, 295-300.

50 A. McLeod, B. Jefferson and E. J. McAdam, Water Res., 2013, 47, 3688-3695.

51 J. Lee, J. Kim and T. Hyeon, Adv. Mater., 2006, 18, 2073-2094.

52 F. Rodriguez-Reinoso and M. Molina-Sabio, Carbon, 1992, 30, 1111-1118.

53 J. Ozaki, N. Endo, W. Ohizumi, K. Igarashi and M. Nakahara, Carbon, 1997, 35, 1031-1033.

54 N. Patel, K. Okabe and A. Oya, Carbon, 2002, 40, 315-320.

55 R. Pekala and D. Schaefer, Macromolecules, 1993, 26, 5487-5493.

56 H. Nishihara, K. Imai, H. Itoi, K. Nomura, K. Takai and T. Kyotani, Tanso, 2017, 2017, 169-174.

57 V. Presser, M. Heon and Y. Gogotsi, Adv. Funct. Mater., 2011, 21, 810-833.

58 Y. Korenblit and G. Yushin, in Carbon Nanomaterials, ed. Y. Gogotsi and V. Presser, 2nd edn, 2014, ch. 11, pp. 303330.

$59 \mathrm{~W} . \mathrm{Gu}$ and G. Yushin, Wiley Interdiscip. Rev.: Energy Environ., 2014, 3, 424-473.

60 N. Texier-Mandoki, J. Dentzer, T. Piquero, S. Saadallah, P. David and C. Vix-Guterl, Carbon, 2004, 42, 2744-2747.

61 E. Masika and R. Mokaya, J. Phys. Chem. C, 2012, 116, 25734-25740.

62 C. F. Martín, M. G. Plaza, J. Pis, F. Rubiera, C. Pevida and T. Centeno, Sep. Purif. Technol., 2010, 74, 225-229.

63 M. Sevilla, J. B. Parra and A. B. Fuertes, ACS Appl. Mater. Interfaces, 2013, 5, 6360-6368.

64 Z. Yang, Y. Xia, X. Sun and R. Mokaya, J. Phys. Chem. B, 2006, 110, 18424-18431.

65 Y. Li, S. Wang, B. Wang, Y. Wang and J. Wei, Nanomaterials, 2020, 10, 174.

66 B. Adeniran and R. Mokaya, Chem. Mater., 2016, 28, 994-1001.

67 S. E. Moradi, Korean J. Chem. Eng., 2014, 31, 1651-1655.

68 A. I. Sultana, N. Saha and M. T. Reza, Sustainability, 2021, 13, 1947.

69 R. Ryoo, S. H. Joo and S. Jun, J. Phys. Chem. B, 1999, 103, 7743-7746.

70 S. Oh and K. Kim, Chem. Commun., 1999, 2177-2178.

71 C. Liang, K. Hong, G. A. Guiochon, J. W. Mays and S. Dai, Angew. Chem., Int. Ed., 2004, 43, 5785-5789. 
72 B. Liu, H. Shioyama, T. Akita and Q. Xu, J. Am. Chem. Soc., 2008, 130, 5390-5391.

73 L. Radhakrishnan, J. Reboul, S. Furukawa, P. Srinivasu, S. Kitagawa and Y. Yamauchi, Chem. Mater., 2011, 23, 1225-1231.

74 H. Nishihara, T. Hirota, K. Matsuura, M. Ohwada, N. Hoshino, T. Akutagawa, T. Higuchi, H. Jinnai, Y. Koseki and H. Kasai, Nat. Commun., 2017, 8, 1-9.

75 M. L. Botome, P. Poletto, J. Junges, D. Perondi, A. Dettmer and M. Godinho, Chem. Eng. J., 2017, 321, 614-621.

76 R. Pedicini, S. Maisano, V. Chiodo, G. Conte, A. Policicchio and R. G. Agostino, Int. J. Hydrogen Energy, 2020, 45, 14038-14047.

77 A. E. Ogungbenro, D. V. Quang, K. A. Al-Ali, L. F. Vega and M. R. M. Abu-Zahra, J. Environ. Chem. Eng., 2018, 6, 4245-4252.

78 H. M. Coromina, D. A. Walsh and R. Mokaya, J. Mater. Chem. A, 2016, 4, 280-289.

79 M. Sevilla, A. B. Fuertes and R. Mokaya, Energy Environ. Sci., 2011, 4, 1400-1410.

80 E. A. Hirst, A. Taylor and R. Mokaya, J. Mater. Chem. A, 2018, 6, 12393-12403.

81 E. Haffner-Staton, N. Balahmar and R. Mokaya, J. Mater. Chem. A, 2016, 4, 13324-13335.

82 L. S. Blankenship and R. Mokaya, Energy Environ. Sci., 2017, 10, 2552-2562.

83 M. Sevilla, N. Alam and R. Mokaya, J. Phys. Chem. C, 2010, 114, 11314-11319.

84 M. Sevilla, R. Foulston and R. Mokaya, Energy Environ. Sci., 2010, 3, 223-227.

85 M. Sevilla and R. Mokaya, J. Mater. Chem., 2011, 21, 4727-4732.

86 S.-Y. Lee and S.-J. Park, J. Solid State Chem., 2010, 183, 2951-2956.

87 S.-Y. Lee and S.-J. Park, Adv. Mater. Res., 2010, 123, 695-698.

88 A. Almasoudi and R. Mokaya, J. Mater. Chem., 2012, 22, 146-152.

89 A. Downie, A. Crosky and P. Munroe, in Biochar for Environmental Management: Science and Technology, ed. J. Lehman and S. Joseph, 2009, ch. 2, p. 14.

90 K. Weber and P. Quicker, Fuel, 2018, 217, 240-261.

91 J. Jagiello, J. Kenvin, A. Celzard and V. Fierro, Carbon, 2019, 144, 206-215.

92 J. F. González, J. M. Encinar, C. M. González-García, E. Sabio, A. Ramiro, J. L. Canito and J. Gañán, Appl. Surf. Sci., 2006, 252, 5999-6004.

93 J. Ganan, J. Gonzalez, C. Gonzalez-Garcia, A. Ramiro, E. Sabio and S. Roman, Appl. Surf. Sci., 2006, 252, 5988-5992.

94 S. Osswald, C. Portet, Y. Gogotsi, G. Laudisio, J. Singer, J. Fischer, V. Sokolov, J. Kukushkina and A. Kravchik, J. Solid State Chem., 2009, 182, 1733-1741.

95 R. Ströbel, L. Jörissen, T. Schliermann, V. Trapp, W. Schütz, K. Bohmhammel, G. Wolf and J. Garche, J. Power Sources, 1999, 84, 221-224.
96 N. P. Wickramaratne and M. Jaroniec, J. Mater. Chem. A, 2013, 1, 112-116.

97 V. Presser, J. McDonough, S.-H. Yeon and Y. Gogotsi, Energy Environ. Sci., 2011, 4, 3059-3066.

98 N. Balahmar and R. Mokaya, J. Mater. Chem. A, 2019, 7, 17466-17479.

99 M. G. Plaza, S. Garcia, F. Rubiera, J. J. Pis and C. Pevida, Chem. Eng. J., 2010, 163, 41-47.

100 H. An, B. Feng and S. Su, Int. J. Greenhouse Gas Control, 2011, 5, 16-25.

101 G. Sdanghi, R. L. Canevesi, A. Celzard, M. Thommes and V. Fierro, Carbon, 2020, 6, 46.

102 B. Feng and S. K. Bhatia, Carbon, 2003, 41, 507-523.

103 E. A. Dawson, G. Parkes, P. A. Barnes and M. J. Chinn, Carbon, 2003, 41, 571-578.

104 S. K. Ryu, H. Jin, D. Gondy, N. Pusset and P. Ehrburger, Carbon, 1993, 31, 841-842.

105 F. Rodriguez-Reinoso, M. Molina-Sabio and M. González, Carbon, 1995, 33, 15-23.

106 C.-F. Chang, C.-Y. Chang and W.-T. Tsai, J. Colloid Interface Sci., 2000, 232, 45-49.

107 M. M. Johns, W. E. Marshall and C. A. Toles, J. Chem. Technol. Biotechnol., 1999, 74, 1037-1044.

108 S. Román, J. F. González, C. M. González-García and F. Zamora, Fuel Process. Technol., 2008, 89, 715-720.

109 H. Wang, Q. Gao and J. Hu, J. Am. Chem. Soc., 2009, 131, 7016-7022.

110 M. Jagtoyen and F. Derbyshire, Carbon, 1998, 36, 1085-1097.

111 T. K. Das, S. Banerjee, P. Sharma, V. Sudarsan and P. U. Sastry, Int. J. Hydrogen Energy, 2018, 43, 8385-8394.

112 F. Caturla, M. Molina-Sabio and F. Rodriguez-Reinoso, Carbon, 1991, 29, 999-1007.

113 M. Molina-Sabio and F. Rodriguez-Reinoso, Colloids Surf., A, 2004, 241, 15-25.

114 J. Wang and S. Kaskel, J. Mater. Chem., 2012, 22, 23710-23725.

115 T. Otowa, R. Tanibata and M. Itoh, Gas Sep. Purif., 1993, 7, 241-245.

116 D. Lozano-Castello, J. Calo, D. Cazorla-Amoros and A. Linares-Solano, Carbon, 2007, 45, 2529-2536.

117 E. Raymundo-Pinero, P. Azaïs, T. Cacciaguerra, D. CazorlaAmorós, A. Linares-Solano and F. Béguin, Carbon, 2005, 43, 786-795.

118 W. Qiao, S.-H. Yoon and I. Mochida, Energy Fuels, 2006, 20, 1680-1684.

119 M. Lillo-Ródenas, D. Cazorla-Amorós and A. LinaresSolano, Carbon, 2003, 41, 267-275.

120 M. Lillo-Ródenas, J. Juan-Juan, D. Cazorla-Amorós and A. Linares-Solano, Carbon, 2004, 42, 1371-1375.

121 Y. Yamashita and K. Ouchi, Carbon, 1982, 20, 41-45.

122 S. Kelemen and C. Mims, Surf. Sci., 1983, 133, 71-88.

123 R. Xue and Z. Shen, Carbon, 2003, 41, 1862-1864.

124 E. Fuente, R. R. Gil, R. P. Giron, M. A. Lillo-Ródenas, M. A. Montes-Moran, M. J. Martin and A. Linares-Solano, Carbon, 2010, 48, 1032-1037. 
125 N. Tsubouchi, M. Nishio and Y. Mochizuki, Appl. Surf. Sci., 2016, 371, 301-306.

126 M. Sevilla, P. Valle-Vigón and A. B. Fuertes, Adv. Funct. Mater., 2011, 21, 2781-2787.

127 D. Lozano-Castello, D. Cazorla-Amoros, A. Linares-Solano and D. F. Quinn, Carbon, 2002, 40, 989-1002.

128 W. Zhao, V. Fierro, C. Zlotea, E. Aylon, M. Izquierdo, M. Latroche and A. Celzard, Int. J. Hydrogen Energy, 2011, 36, 11746-11751.

129 W. Zhao, V. Fierro, C. Zlotea, E. Aylon, M. Izquierdo, M. Latroche and A. Celzard, Int. J. Hydrogen Energy, 2011, 36, 5431-5434.

130 W. Zhao, V. Fierro, N. Fernández-Huerta, M. Izquierdo and A. Celzard, Int. J. Hydrogen Energy, 2012, 37, 14278-14284.

131 J.-H. Lee and S.-J. Park, J. Nanosci. Nanotechnol., 2020, 20, 7124-7129.

132 J. Ludwinowicz and M. Jaroniec, Carbon, 2015, 82, 297-303.

133 M. Sevilla, N. Díez and A. B. Fuertes, ChemSusChem, 2021, 14, 94-117.

134 J. V. Guerrera, J. N. Burrow, J. E. Eichler, M. Z. Rahman, M. V. Namireddy, K. A. Friedman, S. S. Coffman, D. C. Calabro and C. B. Mullins, Energy Fuels, 2020, 34, 6101-6112.

135 A. M. Aljumialy and R. Mokaya, Mater. Adv., 2020, 1, 3267-3280.

136 M. Sevilla, A. S. M. Al-Jumialy, A. B. Fuertes and R. Mokaya, ACS Appl. Mater. Interfaces, 2018, 10, 1623-1633.

137 M. Sevilla, G. A. Ferrero and A. B. Fuertes, Carbon, 2017, 114, 50-58.

138 M. Sevilla and A. B. Fuertes, ChemSusChem, 2016, 9, 1880-1888.

139 V. Fierro, V. Torné-Fernández and A. Celzard, Microporous Mesoporous Mater., 2006, 92, 243-250.

140 V. Fierro, V. Torné-Fernández, A. Celzard and D. Montané, J. Hazard. Mater., 2007, 149, 126-133.

141 A. S. Oberoi, J. Andrews, A. L. Chaffee and L. Ciddor, Int. J. Hydrogen Energy, 2016, 41, 23099-23108.

142 N. M. Musyoka, M. Wdowin, K. M. Rambau, W. Franus, R. Panek, J. Madej and D. Czarna-Juszkiewicz, Renewable Energy, 2020, 155, 1264-1271.

143 J. Liu, X. Liu, Y. Sun, C. Sun, H. Liu, L. A. Stevens, K. Li and C. E. Snape, Adv. Sustainable Syst., 2018, 2, 1700115.

144 L.-P. Xiao, Z.-J. Shi, F. Xu and R.-C. Sun, Bioresour. Technol., 2012, 118, 619-623.

145 M. Sevilla and A. B. Fuertes, Chem. - Eur. J., 2009, 15, 4195-4203.

146 M. Sevilla, J. A. Maciá-Agulló and A. B. Fuertes, Biomass Bioenergy, 2011, 35, 3152-3159.

147 M.-M. Titirici and M. Antonietti, Chem. Soc. Rev., 2010, 39, 103-116.

148 W. Ao, J. Fu, X. Mao, Q. Kang, C. Ran, Y. Liu, H. Zhang, Z. Gao, J. Li and G. Liu, Renewable Sustainable Energy Rev., 2018, 92, 958-979.

149 M. Fernanda Gonzalez-Navarro, L. Giraldo and J. Carlos Moreno-Pirajan, J. Anal. Appl. Pyrolysis, 2014, 107, 82-86.
150 X. Fang, G. Li, J. Li, H. Jin, J. Li, V. Jegatheesan, S. Li, H. Wang and M. Yang, Desalin. Water Treat., 2017, 96, 120-127.

151 P. Veerakumar, T. Maiyalagan, B. G. S. Raj, K. Guruprasad, Z. Jiang and K.-C. Lin, Arabian J. Chem., 2020, 13, 2995-3007.

152 L. Li, F. Sun, J. Gao, L. Wang, X. Pi and G. Zhao, RSC Adv., 2018, 8, 14488-14499.

153 J. Y. Lin, Science, 2016, 353, 121-122.

154 D. W. Breck, Zeolite molecular sieves, Wiley, New York, 1974.

155 D. Bastani, N. Esmaeili and M. Asadollahi, J. Ind. Eng. Chem., 2013, 19, 375-393.

156 H. C. Foley, in Perspectives in Molecular Sieve Science, ed. W. H. Flank and T. E. Whyte, American Chemical Society, 1988 , ch. 21, pp. 335-360.

157 P. Serp, in Comprehensive Inorganic Chemistry II, ed. J. Reedijk and K. Poeppelmeier, Elsevier, 2nd edn, 2013, vol. 7, ch. 13, pp. 323-369.

158 J. S. Beck and J. C. Vartuli, Curr. Opin. Solid State Mater. Sci., 1996, 1, 76-87.

159 A. Dyer, An introduction to zeolite molecular sieves, Wiley, United States, 1988.

$160 \mathrm{H}$. Marsh and F. Rodriguez-Reinoso, Activated Carbon, Elsevier Science Ltd., Oxford, UK, 2006, pp. 243-321.

161 A. R. Mohamed, M. Mohammadi and G. N. Darzi, Renewable Sustainable Energy Rev., 2010, 14, 1591-1599.

162 T. Horikawa, J. i. Hayashi and K. Muroyama, Carbon, 2002, 40, 709-714.

163 C. Gomez-de-Salazar, A. Sepúlveda-Escribano and F. Rodriguez-Reinoso, Carbon, 2000, 38, 1889-1892.

164 G. Bello, R. García, R. Arriagada, A. Sepulveda-Escribano and F. Rodriguez-Reinoso, Microporous Mesoporous Mater., 2002, 56, 139-145.

165 T. Maesen, in Introduction to Zeolite Science and Practice, ed. J. Čejka, H. van Bekkum, A. Corma and F. Schüth, Elsevier, Amsterdam, 3rd edn, 2007, ch. 1, pp. 1-12.

$166 \mathrm{~J}$. Liu and J. Yu, in Zeolites and Zeolite-Like Materials, ed. B. F. Sels and L. M. Kustov, Elsevier, 2016, ch. 1, pp. 1-25.

167 D. Barthelmy, Minerals Arranged by the New Dana Classification, http://webmineral.com/danaclass.shtml, accessed 16th March, 2021.

168 D. J. Earl and M. W. Deem, Ind. Eng. Chem. Res., 2006, 45, 5449-5454.

169 C. Baerlocher, L. B. McCusker, W. M. Meier and D. Olson, Database of Zeolite Structures, http://www.iza-structure. org/databases/, accessed March 16th, 2021.

170 N. Kosinov, J. Gascon, F. Kapteijn and E. J. Hensen, J. Membr. Sci., 2016, 499, 65-79.

171 B. Sakintuna and Y. Yürüm, Ind. Eng. Chem. Res., 2005, 44, 2893-2902.

172 J. Miao, Z. L. Lang, T. Y. Xue, Y. Li, Y. W. Li, J. J. Cheng, H. Zhang and Z. K. Tang, Adv. Sci., 2020, 7, 32.

173 J. Rodriguez-Mirasol, T. Cordero, A. L. Radovic and J. Rodriguez, Chem. Mater., 1998, 10, 550-558. 
174 T. Kyotani, T. Nagai, S. Inoue and A. Tomita, Chem. Mater., 1997, 9, 609-615.

175 S. A. Johnson, E. S. Brigham, P. J. Ollivier and T. E. Mallouk, Chem. Mater., 1997, 9, 2448-2458.

176 K. Kim, M. Choi and R. Ryoo, Carbon, 2013, 60, 175-185.

177 H. Nishihara and T. Kyotani, in Novel Carbon Adsorbents, ed. J. Tascón, Elsevier, London, 2012.

178 E. Masika and R. Mokaya, Energy Environ. Sci., 2014, 7, 427-434.

179 Y. Xia, G. S. Walker, D. M. Grant and R. Mokaya, J. Am. Chem. Soc., 2009, 131, 16493-16499.

180 N. Alam and R. Mokaya, Energy Environ. Sci., 2010, 3, 1773-1781.

181 N. Alam and R. Mokaya, Microporous Mesoporous Mater., 2011, 142, 716-724.

182 N. Balahmar, A. M. Lowbridge and R. Mokaya, J. Mater. Chem. A, 2016, 4, 14254-14266.

183 C. Guan, F. Su, X. Zhao and K. Wang, Sep. Purif. Technol., 2008, 64, 124-126.

184 J. Shi, W. Li and D. Li, Colloids Surf., A, 2015, 485, 11-17.

185 R. M. Freire, A. H. de Morais Batista, A. G. de Souza Filho, J. M. Filho, G. D. Saraiva and A. C. Oliveira, Catal. Lett., 2009, 131, 135-145.

186 R. Ruiz-Rosas, M. J. Valero-Romero, D. Salinas-Torres, J. Rodríguez-Mirasol, T. Cordero, E. Morallon and D. Cazorla-Amorós, ChemSusChem, 2014, 7, 1458-1467.

187 M. Valero-Romero, E. Márquez-Franco, J. Bedia, J. RodríguezMirasol and T. Cordero, Microporous Mesoporous Mater., 2014, 196, 68-78.

188 M. Seredych and T. J. Bandosz, Langmuir, 2007, 23, 6033-6041.

189 Y. Lv, Z. Wu, Y. Fang, X. Qian, A. M. Asiri, B. Tu and D. Zhao, Appl. Mater., 2014, 2, 113302.

190 Y. Xia, Z. Yang and R. Mokaya, Chem. Vap. Deposition, 2010, 16, 322-328.

191 T. Kyotani, Z. Ma and A. Tomita, Carbon, 2003, 41, 1451-1459.

192 L. Chen, R. K. Singh and P. Webley, Microporous Mesoporous Mater., 2007, 102, 159-170.

193 T. Aumond, J. Rousseau, Y. Pouilloux, L. Pinard and A. Sachse, Carbon Trends, 2021, 2, 100014.

194 S. Choi, M. A. Alkhabbaz, Y. G. Wang, R. M. Othman and M. Choi, Carbon, 2019, 141, 143-153.

195 P. X. Hou, T. Yamazaki, H. Orikasa and T. Kyotani, Carbon, 2005, 43, 2624-2627.

196 N. Alam and R. Mokaya, Microporous Mesoporous Mater., 2011, 144, 140-147.

197 Z. Yang, Y. Xia and R. Mokaya, J. Am. Chem. Soc., 2007, 129, 1673-1679.

198 A. Pacuła and R. Mokaya, J. Phys. Chem. C, 2008, 112, 2764-2769.

199 A. Almasoudi and R. Mokaya, Microporous Mesoporous Mater., 2014, 195, 258-265.

200 C. Ducrot-Boisgontier, J. Parmentier, A. Faour, J. L. Patarin and G. D. Pirngruber, Energy Fuels, 2010, 24, 3595-3602.

201 Z. Ma, T. Kyotani and A. Tomita, Chem. Commun., 2000, 2365-2366.
202 H.-K. Youn, J. Kim, G. Chandrasekar, H. Jin and W.-S. Ahn, Mater. Lett., 2011, 65, 1772-1774.

203 P.-X. Hou, H. Orikasa, T. Yamazaki, K. Matsuoka, A. Tomita, N. Setoyama, Y. Fukushima and T. Kyotani, Chem. Mater., 2005, 17, 5187-5193.

204 F. Su, J. Zeng, Y. Yu, L. Lv, J. Y. Lee and X. Zhao, Carbon, 2005, 43, 2366-2373.

205 J. Wang, Z. Liu, X. Dong, C.-E. Hsiung, Y. Zhu, L. Liu and Y. Han, J. Mater. Chem. A, 2017, 5, 6860-6865.

206 R. J. Konwar and M. De, Microporous Mesoporous Mater., 2013, 175, 16-24.

207 Y. Li, X. Wang, T. Thersleff, G. Svensson and N. Hedin, ACS Omega, 2019, 4, 9889-9895.

208 M.-C. Silaghi, C. Chizallet and P. Raybaud, Microporous Mesoporous Mater., 2014, 191, 82-96.

209 K. Kim, T. Lee, Y. Kwon, Y. Seo, J. Song, J. K. Park, H. Lee, J. Y. Park, H. Ihee and S. J. Cho, Nature, 2016, 535, 131-135.

210 G.-H. Moon, A. Bähr and H. Tüysüz, Chem. Mater., 2018, 30, 3779-3788.

211 H. Park, S. K. Terhorst, R. K. Bera and R. Ryoo, Carbon, 2019, 155, 570-579.

212 M. De la Casa-Lillo, F. Lamari-Darkrim, D. Cazorla-Amoros and A. Linares-Solano, J. Phys. Chem. B, 2002, 106, 10930-10934.

213 S. S. Samantaray, S. R. Mangisetti and S. Ramaprabhu, J. Alloys Compd., 2019, 789, 800-804.

214 J. B. Condon, Surface Area and Porosity Determination by Phisisorption Measurements and Theory, 2006, ch. 2, pp. 29-53.

215 J. Jagiello and M. Thommes, Carbon, 2004, 42, 1227-1232.

216 I. Cabria, M. J. López and J. A. Alonso, Carbon, 2007, 45, 2649-2658.

217 K. R. Matranga, A. Stella, A. L. Myers and E. D. Glandt, Sep. Sci. Technol., 1992, 27, 1825-1836.

218 M. Thommes, K. Kaneko, A. V. Neimark, J. P. Olivier, F. Rodriguez-Reinoso, J. Rouquerol and K. S. Sing, Pure Appl. Chem., 2015, 87, 1051-1069.

219 J. Li, B. Michalkiewicz, J. Min, C. Ma, X. Chen, J. Gong, E. Mijowska and T. Tang, Chem. Eng. J., 2019, 360, 250-259.

220 L. S. Blankenship, N. Balahmar and R. Mokaya, Nat. Commun., 2017, 8, 1-12.

221 M. Sevilla, R. Mokaya and A. B. Fuertes, Energy Environ. Sci., 2011, 4, 2930-2936.

222 D. R. Lide, Handbook of Chemistry and Physics, CRC Press, United States, 88th edn, 2007.

223 B. E. Poling, J. M. Prausnitz and J. P. O'connell, Properties of gases and liquids, McGraw-Hill Education, 2001.

224 C. Graham, D. A. Imrie and R. E. Raab, Mol. Phys., 1998, 93, 49-56.

225 J. Jagiello, J. Kenvin, C. O. Ania, J. B. Parra, A. Celzard and V. Fierro, Carbon, 2020, 160, 164-175.

226 J. Jagiello, C. Ania, J. B. Parra and C. Cook, Carbon, 2015, 91, 330-337.

227 S. Reljic, E. Jardim, C. Cuadrado-Collados, M. Bayona, M. Martinez-Escandell, J. Silvestre-Albero and F. Rodríguez- 
Reinoso, Porous Materials: Theory and Its Application for Environmental Remediation, 2021, pp. 139-152.

228 M. Jordá-Beneyto, F. Suárez-García, D. Lozano-Castello, D. Cazorla-Amorós and A. Linares-Solano, Carbon, 2007, 45, 293-303.

229 M. Rzepka, P. Lamp and M. De la Casa-Lillo, J. Phys. Chem. $B, 1998,102,10894-10898$.

230 L. Zhou, Y. Zhou and Y. Sun, Int. J. Hydrogen Energy, 2004, 29, 475-479.

231 S. Hlushak, Phys. Chem. Chem. Phys., 2018, 20, 872-888.

232 J. Srenscek-Nazzal and K. Kielbasa, Appl. Surf. Sci., 2019, 494, 137-151.

233 J. Ludwinowicz and M. Jaroniec, Carbon, 2015, 94, 673-679.

234 M. E. Casco, M. Martínez-Escandell, J. Silvestre-Albero and F. Rodríguez-Reinoso, Carbon, 2014, 67, 230-235.

235 K. Sumida, D. L. Rogow, J. A. Mason, T. M. McDonald, E. D. Bloch, Z. R. Herm, T.-H. Bae and J. R. Long, Chem. Rev., 2012, 112, 724-781.

236 J.-R. Li, R. J. Kuppler and H.-C. Zhou, Chem. Soc. Rev., 2009, 38, 1477-1504.

237 M. Cox and R. Mokaya, Sustainable Energy Fuels, 2017, 1, 1414-1424.

238 B. Adeniran and R. Mokaya, Nano Energy, 2015, 16, 173-185.

239 Z. Tan and K. E. Gubbins, J. Phys. Chem., 1990, 94, 6061-6069.

240 C. M. Simon, J. Kim, D. A. Gomez-Gualdron, J. S. Camp, Y. G. Chung, R. L. Martin, R. Mercado, M. W. Deem, D. Gunter and M. Haranczyk, Energy Environ. Sci., 2015, 8, 1190-1199.

241 S. Biloé, V. Goetz and A. Guillot, Carbon, 2002, 40, 1295-1308. 242 P. Bénard and R. Chahine, Scr. Mater., 2007, 56, 803-808.

243 M. I. M. Kusdhany and S. M. Lyth, Carbon, 2021, 179, 190-201.

244 M. Sevilla, W. Sangchoom, N. Balahmar, A. B. Fuertes and R. Mokaya, ACS Sustainable Chem. Eng., 2016, 4, 4710-4716.

245 N. P. Stadie, J. J. Vajo, R. W. Cumberland, A. A. Wilson, C. C. Ahn and B. Fultz, Langmuir, 2012, 28, 10057-10063.

246 A. J. Lachawiec Jr and R. T. Yang, Langmuir, 2008, 24, 6159-6165.

247 H. Nishihara, P.-X. Hou, L.-X. Li, M. Ito, M. Uchiyama, T. Kaburagi, A. Ikura, J. Katamura, T. Kawarada, K. Mizuuchi and T. Kyotani, J. Phys. Chem. C, 2009, 113, 3189-3196.

248 N. Balahmar, A. C. Mitchell and R. Mokaya, Adv. Energy Mater., 2015, 5, 1500867.

249 K. Xia, R. Xiong, Y. Chen, D. Liu, Q. Tian, Q. Gao, B. Han and C. Zhou, Colloids Surf., A, 2021, 126640.

250 X. Ma, R. Chen, K. Zhou, Q. Wu, H. Li, Z. Zeng and L. Li, ACS Sustainable Chem. Eng., 2020, 8, 11721-11728.

251 Z. Zhang, D. Luo, G. Lui, G. Li, G. Jiang, Z. P. Cano, Y.-P. Deng, X. Du, S. Yin, Y. Chen, M. Zhang, Z. Yan and Z. Chen, Carbon, 2019, 143, 531-541.

252 J. Singh, S. Basu and H. Bhunia, J. Taiwan Inst. Chem. Eng., 2019, 102, 438-447.
253 L. Wang and R. T. Yang, J. Phys. Chem. C, 2012, 116, 1099-1106.

254 J. E. Park, G. B. Lee, S. Y. Hwang, J. H. Kim, B. U. Hong, H. Kim and S. Kim, Appl. Sci., 2018, 8, 1596.

255 N. Byamba-Ochir, W. G. Shim, M. S. Balathanigaimani and H. Moon, Appl. Energy, 2017, 190, 257-265.

256 I. Susanti and N. Widiastuti, Malaysian J. Fundament. Appl. Sci., 2019, 15, 249-253.

257 J. Cui, K. Zhang, X. Zhang and Y. Lee, Microporous Mesoporous Mater., 2020, 295, 109947.

258 C. Guan, L. S. Loo, K. Wang and C. Yang, Energy Convers. Manage., 2011, 52, 1258-1262.

259 L. Giraldo and J. C. Moreno-Piraján, Mater. Sci. Appl., 2011, 2, 331.

260 I. Men'shchikov, A. Shiryaev, A. Shkolin, V. Vysotskii, E. Khozina and A. Fomkin, Korean J. Chem. Eng., 2021, 38, 276-291.

261 Z. Zhang, Z. P. Cano, D. Luo, H. Dou, A. Yu and Z. Chen, J. Mater. Chem. A, 2019, 7, 20985-21003.

262 F. Rodriguez-Reinoso, J. de, D. Lopez-Gonzalez and C. Berenguer, Carbon, 1982, 20, 513-518.

263 W. Hao, E. Björkman, M. Lilliestråle and N. Hedin, Appl. Energy, 2013, 112, 526-532.

264 J. Jagiello, Langmuir, 1994, 10, 2778-2785.

265 J. Garrido, A. Linares-Solano, J. Martin-Martinez, M. Molina-Sabio, F. Rodriguez-Reinoso and R. Torregrosa, Langmuir, 1987, 3, 76-81.

266 D. Grau-Marin, J. Silvestre-Albero, E. O. Jardim, J. Jagiello, W. R. Betz and L. E. Peña, Carbon, 2020, 157, 495-505.

267 D. Lozano-Castelló, D. Cazorla-Amorós and A. LinaresSolano, Carbon, 2004, 42, 1233-1242.

268 R. H. Orcutt, J. Chem. Phys., 1963, 39, 605-608.

269 V. W. Couling and S. S. Ntombela, Chem. Phys. Lett., 2014, 614, 41-44.

270 S. Brunauer, P. H. Emmett and E. Teller, J. Am. Chem. Soc., 1938, 60, 309-319.

271 J. Rouquerol, P. Llewellyn and F. Rouquerol, Stud. Surf. Sci. Catal., 2007, 160, 49-56.

272 J. Rouquerol, F. Rouquerol, P. Llewellyn, G. Maurin and K. S. Sing, Adsorption by powders and porous solids: principles, methodology and applications, Academic Press, 2013.

273 J. Osterrieth, J. Rampersad, D. G. Madden, N. Rampal, L. Skoric, B. Connolly, M. Allendorf, V. Stavila, J. Snider, R. Ameloot, J. Marreiros, C. O. Ania, D. C. S. Azevedo, E. Vilarrasa-García, B. F. Santos, X.-H. Bu, X. Zang, H. Bunzen, N. Champness, S. L. Griffin, B. Chen, R.-B. Lin, B. Coasne, S. M. Cohen, J. C. Moreton, Y. J. Colon, L. Chen, R. Clowes, F.-X. Coudert, Y. Cui, B. Hou, D. D'Alessandro, P. W. Doheny, M. Dinca, C. Sun, C. Doonan, M. Huxley, J. D. Evans, P. Falcaro, R. Riccò, O. K. Farha, K. B. Idrees, T. Islamoglu, P. Feng, H. Yang, R. Forgan, D. Bara, S. Furukawa, E. Sanchez, J. Gascon, S. Telalovic, S. K. Ghosha, S. Mukherjee, M. R. Hill, M. M. Sadiq, P. Horcajada, P. Salcedo-Abraira, K. Kaneko, R. Kukobat, J. Kenvin, S. Keskin, S. Kitagawa, K. Otake, R. P. Lively, S. J. A. DeWitt, P. L. Llewellyn, 
B. Lotsch, S. T. Emmerling, A. Pütz, C. Martí-Gastaldo, N. Muñoz, J. Garcia-Martinez, N. Linares, D. Maspoch, J. A. Suarez, P. Moghadam, R. Oktavian, R. Morris, P. Wheatley, J. Navarro, C. Petit, D. Danaci, M. Rosseinsky, A. Katsoulidis, M. Schroder, X. Han, S. Yang, C. Serre, G. Mouchaham, D. Sholl, R. Thyagarajan, D. Siderius, R. Q. Snurr, R. B. Goncalves, S. G. Telfer, S. J. Lee, V. Ting, J. Rowlandson, T. Uemura, T. Iiyuka, M. V. D. Veen, D. Rega, V. Vanspeybroeck, A. Lamaire, S. Rogge, K. Walton, L. W. Bingel, S. Wuttke, J. Andreo, O. Yaghi, B. Zhang, C. Yavuz, T. Nguyen, F. Zamora, C. Montoro, H.-C. Zhou, K. Angelo and D. Fairen-Jimenez, unpublished work.

274 A. Marczewski, Adsorption Glossary, 2002.

275 J. Villarroel-Rocha, D. Barrera, A. A. G. Blanco, M. E. R. Jalil and K. Sapag, Adsorpt. Sci. Technol., 2013, 31, 165-183.

276 M. Occelli, J. Olivier, J. Perdigon-Melon and A. Auroux, Langmuir, 2002, 18, 9816-9823.

277 M. M. Dubinin and V. A. Astakhov, in Molecular Sieve Zeolites-II, ed. E. M. Flanigen and L. B. Sand, ACS Publications, United States, 1971, ch. 44, pp. 69-85.

278 G. Horváth and K. Kawazoe, J. Chem. Eng. Jpn., 1983, 16, 470-475.

279 E. P. Barrett, L. G. Joyner and P. P. Halenda, J. Am. Chem. Soc., 1951, 73, 373-380.

280 P. Ramirez-Vidal, R. L. Canevesi, G. Sdanghi, S. Schaefer, G. Maranzana, A. Celzard and V. Fierro, ACS Appl. Mater. Interfaces, 2021, 13, 12562-12574.

$281 \mathrm{~J}$. Jagiello and M. Thommes, International Conference on Carbon for Energy Storage and Environment Protection, Orleans, France, 2005.

282 M. Kwiatkowski and D. Kalderis, Carbon Lett., 2020, 30, 325-329.

283 T. Tian, Z. Zeng, D. Vulpe, M. E. Casco, G. Divitini, P. A. Midgley, J. Silvestre-Albero, J.-C. Tan, P. Z. Moghadam and D. Fairen-Jimenez, Nat. Mater., 2018, 17, 174-179.

284 J. Marco-Lozar, J. Juan-Juan, F. Suárez-García, D. CazorlaAmorós and A. Linares-Solano, Int. J. Hydrogen Energy, 2012, 37, 2370-2381.

285 J. Marco-Lozar, M. Kunowsky, F. Suarez-Garcia, J. Carruthers and A. Linares-Solano, Energy Environ. Sci., 2012, 5, 9833-9842.

286 J. Juan-Juan, J. Marco-Lozar, F. Suárez-García, D. CazorlaAmorós and A. Linares-Solano, Carbon, 2010, 48, 2906-2909.

287 Y. Song, X. Zhou and J. A. Wang, Energy Sources, Part A, 2021, 43, 1337-1347.

288 C. Ge, D. Lian, S. Cui, J. Gao and J. Lu, Processes, 2019, 7, 592.

289 E. Mehrvarz, A. A. Ghoreyshi and M. Jahanshahi, Front. Chem. Sci. Eng., 2017, 11, 252-265.

290 K. Adlak, R. Chandra, V. K. Vijay and K. K. Pant, J. Anal. Appl. Pyrolysis, 2021, 105102.

291 P. Wang, G. Zhang, W. Chen, Q. Chen, H. Jiao, L. Liu, X. Wang and X. Deng, ACS Omega, 2020, 5, 23460-23467.

292 O. Boujibar, A. Souikny, F. Ghamouss, O. Achak, M. Dahbi and T. Chafik, J. Environ. Chem. Eng., 2018, 6, 1995-2002.
293 E. García-Díez, S. Schaefer, A. Sanchez-Sanchez, A. Celzard, V. Fierro, M. M. Maroto-Valer and S. García, ACS Appl. Mater. Interfaces, 2019, 11, 36789-36799.

294 X. Liu, C. Zhang, Z. Geng and M. Cai, Microporous Mesoporous Mater., 2014, 194, 60-65.

295 W. Shi, Q. Zhang, S. Liu, S. Su, B. Chang and B. Yang, J. Colloid Interface Sci., 2021, 600, 670-680.

296 A. Taylor, PhD thesis, University of Nottingham, 2019.

297 M. Xia, W. Chen, J. Wu, Y. Chen, H. Yang, X. Chen, D. Zhu and H. Chen, Fuel, 2021, 291, 120185.

298 X.-F. Wang, L. Xiong, J.-J. Zhong, L. Jin, J.-L. Yan, B. Mu, Y.-G. Zhang and S.-L. Song, Ind. Eng. Chem. Res., 2020, 59, 18106-18114.

299 J. Deng, T. Xiong, F. Xu, M. Li, C. Han, Y. Gong, H. Wang and Y. Wang, Green Chem., 2015, 17, 4053-4060.

300 J.-S. Wei, S. Wan, P. Zhang, H. Ding, X.-B. Chen, H.-M. Xiong, S. Gao and X. Wei, New J. Chem., 2018, 42, 6763-6769.

301 J. Wang, Q. Yang, W. Yang, H. Pei, L. Zhang, T. Zhang, N. Hu, Y. Suo and J. Wang, J. Mater. Chem. A, 2018, 6, 16690-16698.

302 A. Rehman, Y.-J. Heo, G. Nazir and S.-J. Park, Carbon, 2021, 172, 71-82.

303 Z. Han, H. Yu, C. Li and S. Zhou, Appl. Surf. Sci., 2021, 544, 148963.

$304 \mathrm{Z}$. Hu and M. P. Srinivasan, Microporous Mesoporous Mater., 2001, 43, 267-275.

305 Z. Hu, H. Guo, M. Srinivasan and N. Yaming, Sep. Purif. Technol., 2003, 31, 47-52.

306 A. Arami-Niya, W. M. A. W. Daud, F. S. Mjalli, F. Abnisa and M. S. Shafeeyan, Chem. Eng. Res. Des., 2012, 90, 776-784.

307 A. B. Fuertes and M. Sevilla, Carbon, 2015, 94, 41-52.

308 X. Ma, Y. Li, M. Cao and C. Hu, J. Mater. Chem. A, 2014, 2, 4819-4826.

309 W. Hu, W. Zhang, M. Zheng, Y. Xiao, H. Dong, Y. Liang, $\mathrm{H}$. $\mathrm{Hu}$ and $\mathrm{Y}$. Liu, Int. J. Hydrogen Energy, 2021, 46, 896-905.

310 C. Bommier, R. Xu, W. Wang, X. Wang, D. Wen, J. Lu and X. Ji, Nano Energy, 2015, 13, 709-717.

311 H. Yang, R. Yan, H. Chen, D. H. Lee and C. Zheng, Fuel, 2007, 86, 1781-1788.

312 C. Xia and S. Q. Shi, Green Chem., 2016, 18, 2063-2071.

313 A. Ariharan, K. Ramesh, R. Vinayagamoorthi, M. S. Rani, B. Viswanathan, S. Ramaprabhu and V. Nandhakumar, J. Energy Storage, 2021, 35, 102185.

314 A. Ariharan, B. Viswanathan and V. Nandhakumar, Indian J. Chem., Sect. A: Inorg., Bio-inorg., Phys., Theor. Anal. Chem., 2016, 55, 649-656.

315 M. Sevilla and A. B. Fuertes, J. Mater. Chem. A, 2013, 1, 13738-13741.

316 W. Yang, W. Yang, F. Ding, L. Sang, Z. Ma and G. Shao, Carbon, 2017, 111, 419-427.

317 M. Sevilla and A. B. Fuertes, ACS Nano, 2014, 8, 5069-5078.

318 T. Tsumura, A. Arikawa, T. Kinumoto, Y. Arai, T. Morishita, H. Orikasa, M. Inagaki and M. Toyoda, Mater. Chem. Phys., 2014, 147, 1175-1182. 
319 G. A. Ferrero, A. B. Fuertes, M. Sevilla and M.-M. Titirici, Carbon, 2016, 106, 179-187.

320 G. Ferrero, M. Sevilla and A. Fuertes, Carbon, 2015, 88, 239-251.

321 A. B. Fuertes and M. Sevilla, ACS Appl. Mater. Interfaces, 2015, 7, 4344-4353.

322 T. Yang, W. Li, M. Su, Y. Liu and M. Liu, New J. Chem., 2020, 44, 7968-7975.

323 A. Fuertes, G. Ferrero and M. Sevilla, J. Mater. Chem. A, 2014, 2, 14439-14448.

324 H. Luo, Y. Yang, X. Zhao, J. Zhang and Y. Chen, Electrochim. Acta, 2015, 169, 13-21.

325 D. Puthusseri, V. Aravindan, S. Madhavi and S. Ogale, Energy Environ. Sci., 2014, 7, 728-735.

326 A. D. Roberts, X. Li and H. Zhang, Carbon, 2015, 95, 268-278.

327 P. Yadav, A. Banerjee, S. Unni, J. Jog, S. Kurungot and S. Ogale, ChemSusChem, 2012, 5, 2159-2164.

328 D. Hines, A. Bagreev and T. J. Bandosz, Langmuir, 2004, 20, 3388-3397.

329 L. Tong, L.-L. Zhang, Y.-C. Wang, L.-Y. Wan, Q.-Q. Yan, C. Hua, C.-J. Jiao, Z.-Y. Zhou, Y.-W. Ding and B. Liu, ACS Appl. Mater. Interfaces, 2020, 12, 25211-25220.

330 W. Li, F. Zhang, Y. Dou, Z. Wu, H. Liu, X. Qian, D. Gu, Y. Xia, B. Tu and D. Zhao, Adv. Energy Mater., 2011, 1, 382-386.

331 B. Yang, J. Chen, S. Lei, R. Guo, H. Li, S. Shi and X. Yan, Adv. Energy Mater., 2018, 8, 1702409.

332 Y. Wang, H. Wang, H. Wang, M. Zhang, X. Liang, K. Xia and Y. Zhang, ACS Appl. Mater. Interfaces, 2019, 11, 20272-20280.

333 N. Wang, Y. Wang, X. Xu, T. Liao, Y. Du, Z. Bai and S. Dou, ACS Appl. Mater. Interfaces, 2018, 10, 9353-9361.

334 J. K. Guo, J. Liu and L. B. Kong, ChemElectroChem, 2020, 7, 2592-2598.

335 M. Sevilla, G. A. Ferrero, N. Diez and A. B. Fuertes, Carbon, 2018, 131, 193-200.

336 D. Li, X. Ren, Q. Ai, Q. Sun, L. Zhu, Y. Liu, Z. Liang, R. Peng, P. Si and J. Lou, Adv. Energy Mater., 2018, 8, 1802386.

337 B. Adeniran, E. Masika and R. Mokaya, J. Mater. Chem. A, 2014, 2, 14696-14710.

338 J. Deng, T. Xiong, H. Wang, A. Zheng and Y. Wang, ACS Sustainable Chem. Eng., 2016, 4, 3750-3756.

339 N. Balahmar, A. S. Al-Jumialy and R. Mokaya, J. Mater. Chem. A, 2017, 5, 12330-12339.

340 K. M. Rambau, N. M. Musyoka, N. Manyala, J. Ren and H. W. Langmi, Mater. Today: Proc., 2018, 5, 10505-10513.

341 E. E. Taylor, K. Garman and N. P. Stadie, Chem. Mater., 2020, 32, 2742-2752.

342 R. K. Bera, H. Park, S. H. Ko and R. Ryoo, RSC Adv., 2020, 10, 32290-32295.

343 H. Park, J. Bang, S. W. Han, R. K. Bera, K. Kim and R. Ryoo, Microporous Mesoporous Mater., 2021, 318, 111038.

344 R. S. Ambekar, E. F. Oliveira, B. Kushwaha, V. Pal, L. D. Machado, S. M. Sajadi, R. H. Baughman, P. M. Ajayan, A. K. Roy and D. S. Galvao, Addit. Manuf., 2021, 37, 101628.
345 H. Tanaka, T. Seto, H. Nishihara, T. Kyotani and M. T. Miyahara, Carbon, 2021, 175, 609.

346 R. Wijiyanti, T. Gunawan, N. S. Nasri, Z. A. Karim, A. F. Ismail and N. Widiastuti, Indones. J. Chem., 2020, 20, 29-42.

347 D. Tiwari, H. Bhunia and P. K. Bajpai, J. Indian Chem. Soc., 2018, 95, 247-252.

348 N. M. Musyoka, K. M. Rambau, N. Manyala, J. W. Ren, H. W. Langmi and M. K. Mathe, J. Environ. Sci. Health, Part A: Toxic/Hazard. Subst. Environ. Eng., 2018, 53, 1022-1028.

349 T. Gunawan, R. Wijiyanti and N. Widiastuti, RSC Adv., 2018, 8, 41594-41602.

350 J. Rangel-Sequeda, M. Loredo-Cancino, V. I. A. Maté, J. A. D. Dobladez, D. A. De Haro-Del Rio, J. J. Salazar-Rábago and E. Soto-Regalado, Water, Air, Soil Pollut., 2021, 232, 1-18.

351 N. P. Stadie, M. Murialdo, C. C. Ahn and B. Fultz, J. Am. Chem. Soc., 2013, 135, 990-993.

352 S. T. J. Dewi and N. Widiastuti, in 3rd International Seminar on Chemistry: Green Chemistry and Its Role for Sustainability, ed. Y. Kusumawati, S. Fatmawati, A. S. Purnomo, F. Kurniawan and H. Juwono, Amer Inst Physics, Melville, 2018, vol. 2049.

353 C. Xue, H. Zhu, T. Xu, E. Wang, B. Xiao, X. Liu, X. Hao and G. Guan, $R S C$ Adv., 2017, 7, 24195-24203.

354 X. Ma, L. Li, R. Chen, C. Wang, H. Li and H. Li, Chem. Asian J., 2018, 13, 2069-2076.

355 A. Garsuch, O. Klepel, R. R. Sattler, C. Berger and R. Gläser, Carbon, 2006, 44, 593-596.

356 R. Baur and R. Krishna, Catal. Today, 2005, 105, 173-179.

357 A. Sachse and J. Garcia-Martinez, Chem. Mater., 2017, 29, 3827-3853.

358 P. Annamalai, N. M. Musyoka, J. W. Ren, H. W. Langmi, M. Mathe, D. Bessarabov and L. F. Petrik, Res. Chem. Intermed., 2017, 43, 4095-4102.

359 M. Mazaj, M. Bjelica, E. Žagar, N. Z. Logar and S. Kovačič, ChemSusChem, 2020, 13, 2089-2097.

360 A. Celzard and V. Fierro, Energy Fuels, 2005, 19, 573-583.

361 P.-X. Hou, H. Orikasa, H. Itoi, H. Nishihara and T. Kyotani, Carbon, 2007, 45, 2011-2016.

362 J. Shao, X. Xiao, X. Fan, X. Huang, B. Zhai, S. Li, H. Ge, Q. Wang and L. Chen, Nano Energy, 2015, 15, 244-255.

363 A. Almasoudi and R. Mokaya, J. Mater. Chem. A, 2014, 2, 10960-10968.

364 A. Gabe, M. Ouzzine, E. E. Taylor, N. P. Stadie, N. Uchiyama, T. Kanai, Y. Nishina, H. Tanaka, Z.-Z. Pan and T. Kyotani, J. Mater. Chem. A, 2021, 9, 7503-7507.

365 J. Jiang, Q. Gao, K. Xia and J. Hu, Microporous Mesoporous Mater., 2009, 118, 28-34.

366 K. Xia, Q. Gao, S. Song, C. Wu, J. Jiang, J. Hu and L. Gao, Int. J. Hydrogen Energy, 2008, 33, 116-123.

367 H. Wang, Q. Gao and J. Hu, Microporous Mesoporous Mater., 2010, 131, 89-96.

368 U. Anggarini, E. Agustina and N. Widiastuti, Indones. J. Chem., 2015, 15, 315-318.

369 K. Matsuoka, Y. Yamagishi, T. Yamazaki, N. Setoyama, A. Tomita and T. Kyotani, Carbon, 2005, 43, 876-879. 